\title{
Влияние корпоративных новостей на рыночную стоимость компаний
}

\author{
Солодухина А.В. ${ }^{8}$, Репин Д.В. ${ }^{9}$
}

И деловое, и академическое сообщества сходятся в том, что объявляемые компанией новости влияют на ее рыночную стоимость. Эмпирические данные показывают, что корпоративные новости, попадая на рынок, зачастую вызывают достаточно предсказуемую реакцию инвесторов. Эта реакция зависит от множества факторов: тип новости (хорошая/плохая), тип события, о котором сообщается в новости, аналитическое покрытие компании, предшествующие прогнозы и рекомендации аналитиков, состояние рынка (спад, подъем), тип акиий компании и еще более десятка других обстоятельств.

В данной статье мы предприняли попытку объединить разрозненные эмпирические данные, выявить значимые факторы и установить характер их влияния на реакцию рынка - $и$ в итоге представить цельную картину. Это позволило нам разработать концептуальную модель, которая описывает, какого типа новость и при каких условиях будет влиять тем или иным образом на рыночную стоимость компании. Также мы предлагаем качественную методику анализа влияния новости на рыночную стоимость компании.

Представленные в работе модель и методика призваны помочь компаниям заранее определять реакиию рынка на объявление того или иного события, корректировать возможные негативные последствия и в конечном итоге более эффективно управлять своей рыночной стоимостью.

\section{JEL: G39}

Ключевые слова: управление стоимостью компании, поведенческие финансы, корпоративные новости, объявление новостей, отношения с инвесторами

\section{Введение}

Цены акций, по мнению многих исследователей, являются предсказуемыми. К этому выводу подталкивают многочисленные закономерности, обнаруженные учеными на реальных эмпирических данных многих фондовых рынков по всему миру. К таким закономерностям относятся, к примеру, возвращение к среднему на недельных и долгосрочных (3-5 лет) интервалах и дрифт на интервалах свыше 12 месяцев (смотри работы Де Бондта и Тэйлора [DeBondt and Thaler, 1985], Джегадиша [Jegadeesh, 1990], Ло и Маккинлэй [Lo and MacKinlay, 1990] и Джегадиша и Титмана [Jegadeesh and Titman, 1993]). Некоторые исследования также устанавливали факт дрифта цен акций после объявления важных корпоративных событий (например, исследования Микаэли и др. [Michaely et al., 1995], Икенберри и Рамнат [Ikenberry and Ramnath, 2002], Икенберри и др. [Ikenberry et al., 1996], Лугран и Риттер [Loughran and Ritter, 1995], Спайс и Аффлек-Грейвз [Spiess and Affleck-Graves, 1995] и многие другие). Однако если цена акций предсказуема, т.е. рынок

\footnotetext{
${ }^{8}$ Солодухина Анна Владимировна - аспирантка кафедры «Финансы и кредит» экономического факультета МГУ, автор и преподаватель курса «Поведенческие финансы» на кафедре «Финансы и кредит» экономического факультета МГУ, сотрудник Научно-исследовательской лаборатории корпоративных финансов при факультете экономики ГУ ВШЭ.

${ }^{9}$ Репин Дмитрий Владимирович - PhD, профессор ГУ ВШЭ. Руководитель Бизнес-инкубатора ГУ ВШЭ, один из ведущих специалистов в области поведенческих финансов в России.
} 
однозначно реагирует на определенное событие, тогда торгуемые компании могут использовать эти закономерности в своих интересах, а именно управлять ценой своих акций или по меньшей мере знать заранее, какой эффект последует за тем или иным ее решением или объявлением. Одним из каналов, и пожалуй, наиболее важным из каналов связи информационного пространства компании и рынка, является объявление корпоративных новостей. Изучению влияния объявления корпоративных новостей на цену акций компании посвящены многие исследования. И действительно, чтобы понять, какой эффект оказывают корпоративные новости на цену акций, требуется не одно исследование. Необходимо проанализировать достаточно много аспектов: эмоциональную окраску новости (хорошая она или плохая), содержание новости (т.е. о каком событии в ней сообщается - выпуске нового продукта, слиянии, выкупе акций или забастовке на заводе), контекст выхода новости (т.е. в какой фазе находится фондовый рынок - на спаде, на подъеме), к какому типу относится сама компания (зрелому стабильному или растущему) и много-много других обстоятельств. Поэтому задача комплексного описания влияния корпоративных новостей на рыночную стоимость компании является очень трудной, но и не менее привлекательной с точки зрения практического применения. По этой причине мы взялись за эту задачу и решили свести воедино результаты всех исследований, с тем чтобы получить наиболее полный ответ на данный вопрос. Безусловно, процесс консолидации результатов исследований был не механический. Во-первых, для создания обобщенной модели мы отбирали только те исследования, в которых использовался корректный метод и корректная выборка. Во-вторых, при рассмотрении различных исследований в комплексе возникает синергетический эффект - аналогично тому, как, собирая картинку из отдельных элементов, даже при их нехватке мы понимаем, что изображено на картине, и примерно представляем, что изображено на недостающих элементах.

При написании данной работы было проанализировано 22 исследования, посвященные непосредственно изучению влияния корпоративных новостей на цену акций компании. Полный перечень использованной литературы приведен в конце работы.

\section{Часть 1. Факторы влияния корпоративных новостей на рыночную стоимость компании и их анализ}

\section{1. Краткий обзор факторов}

Изучив исследования, посвященные влиянию корпоративных новостей на рыночную стоимость компании, мы выделили ряд факторов, обуславливающих характер такого влияния.

1. Первый и самый очевидный фактор, который обуславливает направление движения цены акций в результате поступления новости на рынок, - это хорошая или плохая новость объявлена компанией. Как и подсказывает нам логика, в случае хорошей новости рыночная стоимость увеличивается, а в случае плохой - падает. Однако критерии, по которым рынок определяет, хорошая новость или плохая, не столь очевидны и легко конструируемы. Некоторые исследования фиксируют асимметричность реакции рынка на хорошие и плохие новости. Асимметричность означает, что рынок сильнее реагирует на негативные новости (по модулю), чем на хорошие. Влияние новостей на рыночную стоимость компании в зависимости от «знака» новостей затрагивается в огромном количестве работ, однако всякий раз влияние этого фактора изучается в совокупности с другими - например, с типом акций, как в работе Скиннера и Слоуна [Skinner and Sloan, 2002], или с состоянием рынка, как в исследовании Конрада, Корнелла и Ландсмана [Conrad, Cornell and Landsman, 2002]. В связи с этим вычленить отдельно эффект качества новости в таких «комплексных» исследованиях представляется по меньшей мере трудновыполнимой задачей.

2. Следующим фактором, изучаемым экономистами, является степень распространенности новости, т.е. насколько широкому кругу инвесторов доносится новость. 
Данный фактор имеет значение, поскольку именно инвесторы в своей совокупности определяют рыночную стоимость компании на основе получаемой информации. В целях определения степени распространенности новости исследователи используют факт публичного объявления (например, работы Чана [Chan, 2003] и Притамани и Сингала [Pritamani and Singal, 2001]) или наличие аналитического обзора по компании (в частности, Хонг и др. [Hong et al., 2000]).

3. Отдельный большой блок составляют работы, посвященные реакции рынка на новости о различных корпоративных событиях. Как показывают исследования, объявления компании о проведении выкупа собственных акций или изменении дивидендной политики, или эмиссии долговых инструментов и т.д. определенным образом влияют на рыночную стоимость компании. Более того, фиксируемые исследователями зависимости - между типом корпоративного события и характером изменения рыночной стоимости компании являются устойчивыми на разных выборках. Тип события влияет не только на величину изменения рыночной стоимости и его направление, но и на характер реакции инвесторов, а именно будет ли объявление события сопровождаться недостаточной реакцией рынка (underreaction) или чрезмерной реакцией (overreaction). Данный вопрос рассматривается в работах, например, Микаэли и Вомак [Michaely and Womack, 1999], Вомак [Womack, 1996], Микаэли и др. [Michaely et al., 1995], Икенберри и Рамнат [Ikenberry and Ramnath, 2002], и Икенберри и др. [Ikenberry et al., 1996], Лугран и Риттер [Loughran and Ritter, 1995], и Спайс и Аффлек-Грейвз [Spiess and Affleck-Graves, 1995], Бернард и Tомас [Bernard and Thomas, 1989], Риттер [Ritter, 1991] и многих других.

4. Ряд исследований посвящен изучению влияния новостей в зависимости от типа акций компании. В данном случае исследователей интересует, относятся акции компании к так называемым «гламурным» акциям (glamour stocks) или к акциям стоимости (value stocks). Идея такова, что инвесторы по-разному оценивают и реагируют на новости для этих двух типов компаний, поскольку ожидания для этих типов компании также различны и то, что хорошо для зрелой компании (value stocks), не есть хорошо для компании роста (glamour stocks). Здесь можно выделить работы Конрада, Корнелла и Ландсмана [Conrad, Cornell and Landsman, 2002] и Скиннера и Слоуна [Skinner and Sloan, 2002].

5. Еще один фактор, отражающий ожидания и предпочтения инвестора и определяющий характер влияния новости на стоимость компании, — это текущее состояние фондового рынка, т.е. «хорошие» или «плохие» времена переживает в данный момент рынок. Состояние рынка является важным контекстом объявления новостей - на фоне спада и подъема рынка инвесторы по-разному реагируют на хорошие и плохие новости. Этот вопрос рассматривается в работе Конрада, Корнелла и Ландсмана [Conrad, Cornell and Landsman, 2002].

6. Тип инвестора, преобладающий в структуре собственности компании, также определяет характер реакции рыночной стоимости на корпоративные новости. Институциональные и индивидуальные инвесторы располагают различными информационными и денежными ресурсами, используют разные стратегии инвестирования, ориентируются на разные горизонты инвестирования, поэтому теоретически характер реакции разных типов инвесторов на новости должен тоже различаться. Эмпирическая сторона данного вопроса рассмотрена в работах Коэна, Гомперса и Вуолтеенахо [Cohen, Gompers and Vuolteenaho, 2002], Экхольма [Ekholm, 2002] и Ли [Lee, 1992].

7. В работе Конрада, Корнелла и Ландсмана [Conrad, Cornell and Landsman, 2002] тестируется гипотеза о значимости торговой площадки для результатов подобных исследований. То есть авторы предположили, что могут наблюдаться различия между характером связи новостей и изменениями рыночной стоимости компаний в зависимости от биржи, на которой торгуются акции компании. Авторы исследуют реакцию рыночной стоимости на новости на двух торговых площадках: NYSE и Nasdaq. В работе представлены следующие результаты: в целом для обеих подвыборок характерна общая зависимость, т.е. наиболее сильная реакция наблюдается на плохие новости в хорошие времена. Однако есть 
и различия: акции компаний, торгующиеся на Nasdaq, реагируют на новости более сильно и менее стабильно (в данном случае мерой реакции рынка выступает избыточная доходность компании). Так, коэффициенты в регрессионном уравнении при объясняющих переменных UEUP (позитивный шок финансовых результатов) и UEDOWN (негативный шок) для Nasdaq вдвое превышают те же коэффициенты в регрессионном уравнении для NYSE. Это свидетельствует о более высокой чувствительности к новостям торговой системы Nasdaq. Причины такой повышенной чувствительности одной торговой площадки относительно другой для авторов остаются загадкой, и, подводя итоги секции, они оставляют эту задача для дальнейших исследований. Так как других подобных исследований мы не обнаружили, а проработанность вопроса в данной работе весьма невелика, то мы исключим этот фактор из дальнейшего рассмотрения.

Далее мы представим более детальный аналитический обзор по каждому выделенному выше фактору. Нас интересуют результаты наиболее современных и, главное, компетентных научных исследований, которые можно было бы положить в основу связей интегральной модели. Для этого мы изучили методы, гипотезы, выборки каждого исследования и отобрали те из них, которые заслуживают внимания и доверия. Ниже приведены результаты нашего анализа.

\section{2. Фактор № 1: хорошие и плохие новости}

Как уже говорилось, современных научных исследований, посвященных изучению только лишь различий реакции рынка на хорошие и плохие новости, нет. Этот вопрос изучается в комплексе с другими факторами. В частности, Скиннер и Слоун [Skinner and Sloan, 2002] затрагивают его, изучая, как акции разного типа - гламурные акции и акции роста - реагируют на плохие и хорошие новости. В свою очередь Конрад, Корнелл и Ландсман [Conrad, Cornell and Landsman, 2002] сопоставляют реакцию рынка на новости в разных состояниях фондового рынка, а также для разного типа акций. Выделить во многих работах отдельно эффект хороших и плохих новостей не представляется возможным. Редкое исключение составляет исследование Скиннера и Слоуна [Skinner and Sloan, 2002], которое мы рассмотрим чуть позже, после обсуждения более важного вопроса. Таким первоочередным вопросом, который возникает при обсуждении этого фактора, являются критерии хорошей новости и плохой, т.е.: что считать хорошей новостью, а что - плохой? Вопрос не лишний и, кроме того, нетривиальный. Поэтому сделаем краткий аналитический обзор метрик, которыми пользуются исследователи для выполнения эмпирических работ.

В первой группе метрики классифицируют новости на хорошие и плохие в зависимости от заработанной доходности. Метрику, основанную на этом принципе, предлагает, к примеру, Чан [Chan, 2003]. Автор отбирает акции «с новостями» на ежемесячной основе и далее разбивает их на терцили в зависимости от доходности, полученной за этот месяц. По заработанной за месяц доходности делается вывод о «качестве» объявленной новости: если акции компании показывают худшую по рынку доходность, то новости, которые она объявила в этом периоде, определяются как плохие, и наоборот. Так, новости компаний верхнего терциля (т.е. портфеля акций, заработавшего наивысшую доходность по рынку) считаются хорошими, а новости компаний нижнего терциля - плохими.

Немного иной метрикой пользуются Притамани и Сингал [Pritamani and Singal, 2001]. Авторы делят новости на хорошие и плохие на основании знака скорректированной сверхдоходности, заработанной за день объявления новости: если данная сверхдоходность отрицательная, значит, новость плохая, и наоборот.

Доходность, с одной стороны, является верным показателем того, как воспринимает рынок новость - как хорошую или как плохую. Однако, с другой стороны, этот показатель не во всех случаях может быть адекватным, поскольку реакция рынка на новость может проявиться не в том же месяце, а например, раньше, как это часто бывает с объявлениями 
финансовых результатов. Так, официальным объявлениям зачастую предшествуют предварительные сообщения, 75\% которых сосредоточено в промежутке 2 недели до и 2 недели после конца отчетного квартала (см. работы Скиннера [Skinner, 1997] и Соффера и др. [Soffer et al., 2000]), и именно на этот интервал приходится большая часть реакции рынка; между тем в день официального объявления финансовых результатов наблюдается относительно небольшая реакция.

Метрики второй группы основываются на изменениях показателей, которые однозначно, по мнению применяющих их исследователей, классифицируются как хорошая или плохая новость. Примером такой метрики может служить изменение размера дивидендов, которое используют в своем исследовании Котари, Шу и Высоцки [Kothari, Shu and Wysocki, 2008]: рост дивидендных выплат классифицируется как хорошая новость, а их уменьшение - как плохая. Это, казалось бы, естественное деление новостей на хорошие и плохие, однако, не всегда верно. Так, Бейкер и Веглер [Baker and Wurgler, 2004a, 2004b] эмпирически показали, что в разные периоды инвесторы по-разному воспринимают новость о росте и уменьшении дивидендных выплат: иногда инвесторы предпочитают компании, выплачивающие дивиденды, и платят за акции таких компаний так называемую «дивидендную премию»; а иногда инвесторы предпочитают компании, не тратящие ресурсы на выплату дивидендов, и уже эти компании торгуются с премией. Таким образом, в первом случае рост дивидендов воспримется инвесторами как хорошая новость, а во втором случае - как плохая. Это же касается роста прибыли или, скажем увеличения числа магазинов и т.д. В связи с этим такие метрики ненадежны и могут исказить результаты исследования.

Третью группу составляют метрики, построенные, по сути, на ожиданиях инвесторов, которые формируются аналитиками посредством выпуска рекомендаций и прогнозов. В этом случае хорошей новостью является соответствие фактических результатов ожиданиям инвесторов, и плохой - не оправдавшиеся ожидания инвесторов. В связи с этим авторы, предлагающие такие метрики, пользуются терминами «сюрприз» или «шок», обращая внимание читателя на ключевую роль ожиданий при классификации новости. Так, например, Скиннер и Слоун [Skinner and Sloan, 2002] оперируют метрикой «сюрприз доходов» (ES, Earnings surprise) и определяют сюрприз как разность между реальными доходами на акцию (EPS) за квартал и прогнозируемыми (здесь берется медианное значение прогнозов):

$$
E S=\text { ActualEPS }- \text { MedianForecastedEPS. }
$$

В зависимости от знака сюрприза новость классифицируется как хорошая, плохая или нейтральная - если ожидания в точности оправдались.

Очень схожей метрикой пользуются Конрад, Корнелл и Ландсман [Conrad, Cornell and Landsman, 2002]: они предлагают метрику неожиданных прибылей компании (UE, Unexpected Earnings), которая рассчитывается как разница между реальными прибылями компании и ожидаемыми (здесь берется консенсусный прогноз), поделенная на цену акций компании за 6 дней до объявления финансового результата:

$$
U E=(\text { ActualEarnings }- \text { ConsensusForecastedEarnings }) / \operatorname{Pr} \text { ice }(-6) \text {. }
$$

Аналогично знак метрики указывает на то, хорошая новость или плохая.

Метрики данной группы представляют, на наш взгляд, больший интерес, поскольку отражают действительный процесс восприятия и оценивания инвесторами информации. Оценка информации человеком происходит не в абсолютных значениях, а относительно некой планки, установленной человеком в соответствии с его ожиданиями. Хорошая ли оценка четверка? Для троечника, безусловно, да, так как он обычно ждет тройки. Для отличника это, напротив, плохая оценка - он привык получать пятерки. Поэтому известие о четверке троечником воспримется как хорошая новость, а отличником - как плохая. В данном случае планка, относительно которой инвесторы оценивают, хорошая новость или плохая, достаточно конкретна и едина для всех - это прогнозная величина, предложенная аналитиками. Инвесторы формируют свои ожидания согласно аналитическим прогнозам и реализуют соответствующие стратегии, поэтому любая величина (прибыли, роста доходов и т.д.), оказавшаяся ниже ожидаемой, воспринимается ими как плохая. В связи с этим Выпуск \#1(9), 2009 
классификация новостей на хорошие и плохие на основе сопоставления полученных компанией результатов и ожидаемых, на наш взгляд, является наиболее перспективным направлением.

В заключение обсуждения этого фактора обратимся к тому, как влияют плохие и хорошие новости на рыночную стоимость компании. Ответ на этот вопрос в чистом виде мы можем видеть в очень ограниченном количестве исследований, среди которых - работа Скиннера и Слоуна [Skinner and Sloan, 2002]. В качестве новости в данном исследовании выступают объявления компаниями квартальных финансовых результатов; разделение на хорошие и плохие новости основано на ожиданиях, т.е. используется метрика третьей группы. Реакция рынка на хорошие новости (т.е. когда реальные доходы на акцию превышали медианный прогноз этой величины) составляет 5,5\% сверхдоходности за 63 дня, предшествующие объявлению финансового результата за прошедший квартал. Реакция на плохие новости, в свою очередь, составляет $-5,04 \%$ за тот же период. С одной стороны, реакцию можно считать симметричной, поскольку по модулю величина накопленной за исследуемый период сверхдоходности почти одинакова. Однако авторы указывают, что реакция рынка на нейтральную новость (т.е. когда ожидания инвесторов, сформированные прогнозами аналитиков, в точности оправдываются) отлична от $0 \%$ - она смещена относительно 0 и составляет 1,63\%, что уже дает асимметрию: 3,87\% против 6,67\%.

\section{3. Фактор № 2: состояние рынка - подъем и спад}

Сравнительно недавно аналитики фондового рынка и некоторые исследователи начали высказывать предположение, что состояние фондового рынка является важным контекстом восприятия новости инвесторами. Инвесторы воспринимают объявляемую компанией новость не саму по себе, а в комплексе с текущим состоянием фондового рынка. К сожалению, данная проблема комплексного восприятия агрегированного состояния всего рынка и новости, относящейся к отдельной конкретной компании, получила сравнительно мало внимания в научной литературе. Теоретические модели поведения рыночных цен изучают в качестве стимула либо агрегированную, общерыночную информацию, либо частную, относящуюся непосредственно к конкретной компании. Кратко изложим логику формирования реакции инвесторов на новость с учетом текущего состояния рынка в рамках этих двух групп теорий.

- Поведенческий подход. В рамках этого подхода предполагается, что инвесторы склонны делать неверные выводы на основе анализа прошлых результатов деятельности фирмы, в связи с чем после длительного периода позитивных новостей (т.е. после «хороших времен» на рынке) негативные новости оказывают особенно сильное воздействие на доходность акций, т.е. наблюдается эффект корректировки сверхоптимистичных прогнозов.

Отсюда делается предположение, что относительная реакция цен акций на негативные новости должна монотонно возрастать по мере роста фондового рынка.

- Подход, основанный на рациональных моделях смены состояния (rational regimeshifting models) (например, модели Давида [David, 1997] и Веронези [Veronesi, 1999]). В этих моделях инвесторы не уверены относительно текущего состояния рынка. Так как инвесторы не могут наблюдать текущее состояние рынка напрямую, непосредственно, они вынуждены судить о нем по прошлому функционированию рынка. После долгого периода функционирования рынка на уровне выше среднего инвесторы склоняются к мысли, что рынок находится в «хорошем состоянии». В этом случае очередные хорошие новости мало повлияют на убеждения (мнение) инвесторов (и реакция будет тоже незначительная). Плохие новости, в свою очередь, вызывают падение цен на рынке по двум причинам: 1) плохие новости наводят инвесторов на мысль, что рынок не в таком уж хорошем состоянии (вероятность этого утверждения снижается); 2) так как неопределенность состояния экономики повышается, риск-неприемлющие инвесторы начинают требовать более высокую ожидаемую доходность от акций, и ставка дисконтирования повышается. 
Неопределенность относительно состояния экономики и вызывает асимметрию в реакции инвесторов на хорошие новости и плохие. Таким образом, в период, когда инвесторы полагают, что рынок переживает плохие времена, появление хорошей новости увеличивает вероятность того, что рынок вступает в хорошие времена; в этом случае позитивный эффект хорошей новости сводится на нет выросшей ставкой дисконтирования (из-за неопределенности). В случае негативных новостей такого компенсирующего эффекта нет $^{10}$.

Конрад, Корнелл и Ландсман [Conrad, Cornell and Landsman, 2002] обратились к изучению данного вопроса; в частности, они заинтересовались его эмпирической стороной но не с целью проверки двух конкурирующих теорий, а с тем, чтобы в результате выяснить, существует ли необходимость дальнейшего усовершенствования теорий, интегрирования подходов.

Главная цель исследования - проверить, зависит ли реакция доходности на негативные и позитивные новости от состояния фондового рынка и если зависит, то каким образом. Авторами была выдвинута основная гипотеза: разница между силой реакции на хорошие и плохие новости растет с ростом уровня рынка, т.е. степень асимметричности реакции на хорошие и плохие новости тем выше, чем лучше состояние рынка.

Гипотеза тестировалась на данных о 24097 годовых объявлений финансовых результатов за период 1988-1998 годов.

Для классификации новостей на хорошие и плохие используется метрика неожиданных прибылей компании (UE, Unexpected Earnings), которая рассчитывается как разница между реальными прибылями и ожидаемыми (здесь берется консенсусный прогноз), поделенная на цену акций компании за 6 дней до объявления финансового результата:

$$
U E_{i t}=\left(\text { ActualEarnings }_{i t}-\text { ConsensusForecastedEarnings }_{i t}\right) / \operatorname{Pr}_{i c} \text { Cit }_{i t}(-6) \text {. }
$$

Состояние рынка классифицировалось на хорошее и плохое на основе переменной DIFFPE, определяемой как разница между взвешенным по стоимости средним рыночным $\mathrm{P} / \mathrm{E}$ (value-weighted average market $\mathrm{P} / \mathrm{E}$ ratio) в конце каждого месяца, в котором фирмы делали объявления о прибылях, и среднемесячным рыночным $\mathrm{P} / \mathrm{E}$ за предыдущие 12 месяцев. На основе значений DIFFPE выборка была разделена на квинтили, где нижний квинтиль содержит объявления о прибыли, сделанные в период самого низкого DIFFPE (т.е. самые плохие времена), а верхний квинтиль - объявления о прибыли, сделанные в периоды самого высокого DIFFPE (самые хорошие времена).

Далее авторы оценивают по две регрессии для каждой группы объявлений прибыли, где объясняемой переменной является сверхдоходность (RET), рассчитанная за 6 дней, предшествующих объявлению (т.е. с -5-го по 0-й день, где 0-й день - это день объявления).

Результаты регрессионного анализа:

- Авторы отмечают слабую асимметрию реакции рынка на позитивные и негативные новости (поскольку коэффициенты $b_{2}$ и $b_{1}$ различаются не сильно: $b_{2}=0,321$ и $\left.b_{1}=0.241\right)^{11}$. Реакция на плохие и хорошие новости в терминах сверхдоходности (RET) также слабо асимметрична: реакция несколько сильнее для негативных шоков $\left(\mathrm{RET}_{\mathrm{UE}=0}-\mathrm{RET}_{\mathrm{UE}<0}=\right.$ $0,00118=1,18 \%)$, нежели для положительных шоков $\left(\operatorname{RET}_{\mathrm{UE}>0}-\mathrm{RET}_{\mathrm{UE}=0}=0,00096=0,96 \%\right)$.

- Рынок реагирует на плохие новости тем сильнее, чем выше текущий уровень рынка. Коэффициент чувствительности при плохих новостях $b_{2}$ в целом растет при переходе от нижнего квинтиля DIFFPE (которая соответствует плохому состоянию рынка) к верхней

\footnotetext{
10 Эти модели разработаны с целью описания явлений на агрегированном уровне рынка, а не на уровне отдельных фирм. К примеру, эффект ставки дисконтирования действует через рыночную премию за риск. А на нее оказывает влияние общерыночная информация.

11 Заметим, что скорректированный $\mathrm{R}^{2}$ равен всего лишь $0,8 \%$, что чрезвычайно мало. Более того, показатели $\mathrm{R}^{2}$ для обоих регрессионных уравнений практически идентичны: объясняющая сила обеих картин мира (где рынок реагирует одинаково на плохие и хорошие новости (1) и где рынок реагирует по-разному на хорошие и плохие новости и этим определяется избыточная доходность (2)) одинакова, т.е. обе картины одинаково хороши (или же одинаково плохи, что скорее, судя по $\mathrm{R}^{2}$ ).
} 
(которая соответствует хорошему состоянию). (См. табл.1 и рис.1.) Это наблюдение согласуется с предсказаниями и поведенческих моделей, и моделей смены режима.

- Нет четко выраженной зависимости реакции рынка на хорошие новости от состояния рынка (график коэффициента чувствительности при хороших новостях $b_{1}$ напоминает букву $\mathrm{W})$. В результате авторы делают вывод об одинаковой в среднем реакции рынка на хорошие новости (см. табл.1 и рис.1).

- Асимметричность реакции рынка на негативные и позитивные новости усиливается по мере повышения уровня состояния рынка. Единственное исключение составляет среднее состояние рынка: в этом состоянии он реагирует одинаково на плохие и хорошие новости. (см. рис.2).

Таблица 1.

Реакция рынка на хорошие и плохие новости в зависимости от его текущего состояния*

\begin{tabular}{|c|c|c|}
\hline $\begin{array}{c}\text { Уровни состояний } \\
\text { рынка }\end{array}$ & $\begin{array}{c}\text { Хорошая } \\
\text { оовость } \\
(\mathrm{UE}>0)\end{array}$ & $\begin{array}{c}\text { Плохая } \\
\text { новость } \\
(\mathrm{UE}<0)\end{array}$ \\
\hline $\begin{array}{c}\mathbf{1} \\
\text { (плохое состояние } \\
\text { рынка) }\end{array}$ & $\begin{array}{c}0,244 \\
(3,40)\end{array}$ & $\begin{array}{c}0,245 \\
(3,86)\end{array}$ \\
\hline $\mathbf{2}$ & 0,133 & 0,237 \\
$(2,27)$ & $(3,89)$ \\
\hline $\mathbf{3}$ & 0,387 & 0,366 \\
$(5,15)$ & $(4,80)$ \\
\hline $\mathbf{4}$ & 0,168 & 0,335 \\
$(2,17)$ & $(3,56)$ \\
\hline $\mathbf{5}$ & 0,285 & 0,576 \\
$(5,79)$
\end{tabular}

Источник: Conrad, J., Cornell, B., and W. Landsman (2002), When Is Bad News Really Bad News?, The Journal of Finance.

* В ячейках приведены коэффициенты регрессии, интерпретируемые как чувствительность рынка к хорошим новостям $\left(b_{1}\right)$ и к плохим новостям $\left(b_{2}\right)$, и соответствующая $\mathrm{t}$-статистика. 


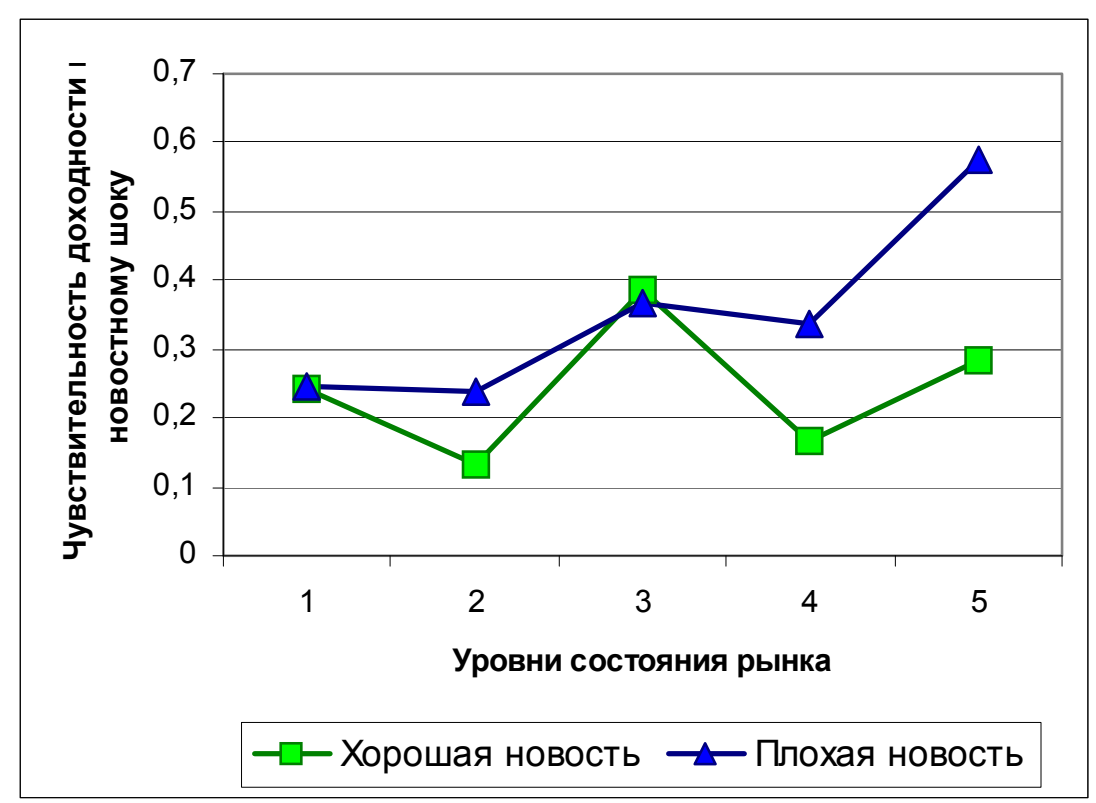

Рис. 1. Изменение силы реакции рынка на позитивные и негативные новостные шоки при изменении состояния рынка - от плохого (квинтиль 1) до хорошего (квинтиль 2)

Источник: график построен по данным исследования Conrad, J., Cornell, B., and W. Landsman (2002), When Is Bad News Really Bad News?, The Journal of Finance.

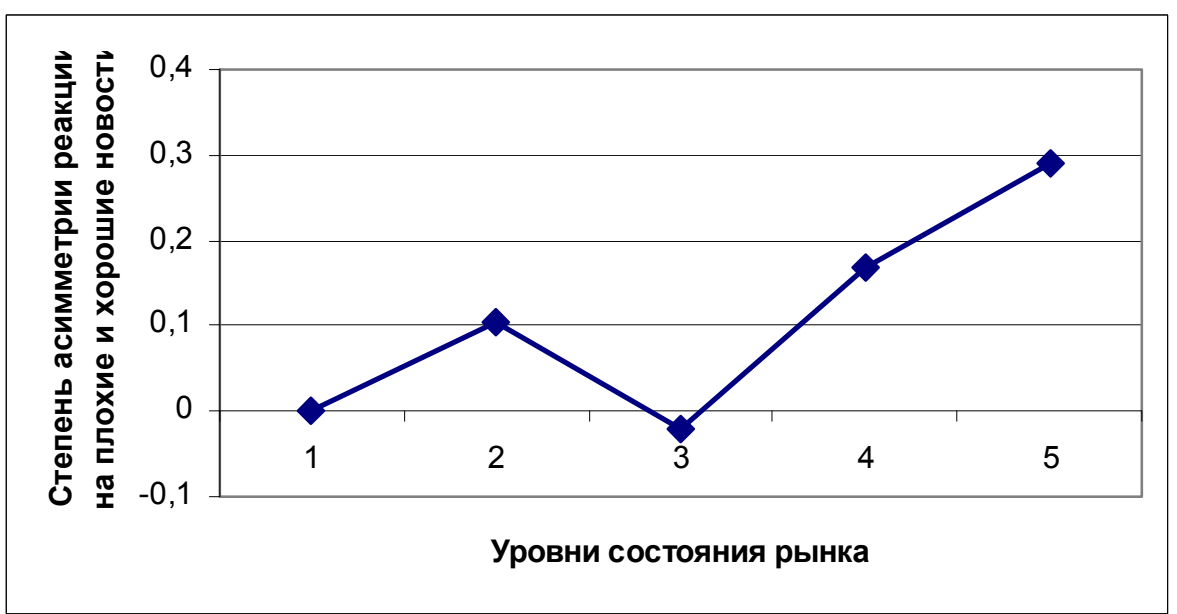

Рис. 2. Степень асимметрии реакции рынка на хорошие и плохие новости в зависимости от текущего состояния фондового рынка на момент объявления новости (степень асимметрии представляет собой разность между коэффициентами чувствительности к хорошим новостям и к плохим в соответствующем квинтиле уровня состояния рынка)

Источник: график построен по данным исследования Conrad, J., Cornell, B., and W. Landsman (2002), When Is Bad News Really Bad News? // The Journal of Finance.

\section{Недостатки исследования:}

1. Выборка получилась такова, что на протяжении 10 лет на рынке наблюдался стабильный рост (лишь один год из десяти отмечен снижением показателя Р/Е - 1995-й), т.е. нет как таковых периодов стагнации и тем более кризиса. Следовательно, полученные пять состояний рынка нельзя интерпретировать как плохое (нижний, первый квинтиль) и хорошее (верхний, пятый квинтиль). Нижний квинтиль можно условно назвать плохим, в абсолюте он приближается к среднему. При интерпретации результатов необходимо это учитывать. 
2. Из выборки были устранены «выбросы», т.е. наблюдения, для которых UE превышает по модулю 0.5. Таким образом, шоки ограничены по величине так, что в исследование попадают только такие объявления финансовых результатов, в которых реальные прибыли несильно (не больше чем на полцены акции) отклоняются от прогнозируемых. Это примешивает к выборке незначительные события, которые искажают результаты. (Заметим, что средний по выборке показатель положительных неожиданных прибылей $\mathrm{UE}=0,0065$ и средний показатель отрицательных $\mathrm{UE}=-0,0096$. На мой взгляд, разрыв реальных доходов с прогнозируемыми в $0,65 \%$ от цены акции слишком незначителен.)

3. Объясняющая способность разных тестируемых картин мира одинакова и очень низка (а именно скорректированный $\mathrm{R}^{2}$ равен всего лишь $0,8 \%$, что чрезвычайно мало). Таким образом, есть основания предположить, что выбранное уравнение регрессии не очень хорошо подходит для исследуемой зависимости.

За неимением других исследований в рамках данной тематики нам сложно в этих условий сделать конечный вывод об эмпирических зависимостях. Перечисленные недостатки исследования ставят под сомнение некоторые полученные в ходе него результаты. Однако мы можем принять, что с ростом рыночного уровня от среднего к высокому наблюдается рост степени асимметрии реакции рынка на хорошие новости и плохие: т.е. рынок сильнее (и отрицательно) реагирует на негативные новости по сравнению с хорошими новостями. При этом под реакцией рынка подразумевается сверхдоходность за 6 дней, предшествующих объявлению финансовых результатов. Что касается влияния новостей на рыночную стоимость в плохие времена фондового рынка, то в этом вопросе необходимо дополнительное исследование на репрезентативных данных.

\section{4. Фактор № 3: тип акции - гламурные акции и акции стоимости}

Вопрос ценообразования акций роста (или «гламурных» акций) относительно акций стоимости является объектом одной из наиболее продолжительных дискуссий в финансовой научной литературе. Начиная с ранних эмпирических работ Басу [Basu, 1983] и Статтмана [Stattman, 1980], исследователи фиксировали странную, с точки зрения традиционной теории финансов, закономерность: сверхдоходность акций стоимости (акции компаний, для которых величина доходов, денежного потока или балансовой стоимости на акцию высока по отношению к цене акций) превышает сверхдоходность гламурных акций (акции компаний, для которых наоборот эта величина относительно мала). Фама и Френч в своих работах [Fama and French, 1992, 1993, 1995, 1996] доказывают, что обнаруженная разница в доходности гламурных акций и акций стоимости представляет собой премию за риск. Однако есть и альтернативная точка зрения, изложенная Лаконишоком, Шляйфером и Вишны [Lakonishok, Shleifer and Vishny, 1994]: эти исследователи полагают, что причина выявленной разницы заключается в неспособности рынка эффективно оценить гламурные акции и акции стоимости. Продолжая мысль, высказанную Лаконишоком и его соавторами, Барберис, Шляйфер и Вишны [Barberis, Shleifer and Vishny, 1998], а также Дэниэл, Хиршляйфер и Субраманиам [Daniel, Hirshleifer and Subrahmanyam, 1998] разработали теоретические модели ценообразования акций в рамках поведенческого подхода, т.е. с учетом особенностей психологии инвесторов. При таком построении модели эффект гламурных акций и акций стоимости возникает автоматически, т.е. только за счет эндогенных переменных модели. Заметим, что Барберис, Шляйфер и Вишны [Barberis, Shleifer and Vishny, 1998] тестировали предсказательную способность своей модели: они генерировали произвольные ряды доходов в рамках модели и тестировали полученные данные на различные эффекты (в частности, на эффект чрезмерной реакции и недостаточной реакции и другие эмпирически выявленные аномалии фондового рынка). В том числе они получили, что доходность дециля акций с максимальным коэффициентом Е/P (которые и называются акциями стоимости) превышает доходность дециля акций с минимальным 
коэффициентом Е/Р (или гламурных акций). Таким образом, есть все основания полагать, что данный эффект не просто случайность или статистическая ошибка, и не результат премии за риск, а систематическая ошибка инвесторов при оценивании акций.

Эмпирические исследования также добавили несколько любопытных штрихов к картине этого вопроса. Так, Ла Порта и др. [La Porta et al., 1997], а также Бернард, Томас и Вален [Bernard, Thomas and Wahlen, 1997] обнаружили, что половина разности в доходностях гламурных акций и акций стоимости приходится на доходность, вызванную объявлением финансовых результатов. Немногим позже Скиннер и Слоун [Skinner and Sloan, 2002] установили, что если включить в исследование период до объявления финансовых результатов и тем самым учесть реакцию рынка, проявляющуюся в движении цен до объявления доходов компании, то разница в доходностях гламурных акций и акций стоимости полностью объясняется такой доходностью «до объявления». Кроме того, Скиннер и Слоун нашли некоторое эмпирическое подтверждение гипотезы Барбериса, Шляйфера и Вишны [Barberis, Shleifer and Vishny, 1998], о модели которых мы говорили выше. Исследование Скиннера и Слоуна [Skinner and Sloan, 2002] само по себе интересно своим подходом, методикой, гипотезами, и, кроме того, результаты представляют для нас особый интерес, поскольку напрямую относятся к вопросу влияния новостей на рыночную стоимость компаний разного типа - роста и стоимости. В связи с этим мы рассмотрим интересующие нас гипотезы и результаты более подробно.

В исследовании используется выборка из 103274 квартальных объявлений финансовых результатов компаний с аналитическим покрытием и цены акций этих компаний за период 1984-1996 годов. Скиннер и Слоун формулируют основную гипотезу своего исследования следующим образом: худшие результаты гламурных акций связаны с ошибками инвесторов в ожиданиях относительно перспектив компании. При этом авторы определяют сюрприз (ES, Earnings surprise) как разность между реальными доходами на акцию (EPS) за квартал и прогнозируемыми (здесь берется медиана). В зависимости от знака сюрприза новость классифицируется как хорошая, плохая или нейтральная - если ожидания в точности оправдались.

Авторы прогнозируют следующие результаты:

1) гламурные акции будут демонстрировать асимметрично большую отрицательную доходность после объявления плохих новостей-сюрпризов;

2) вся разница в доходности между гламурными акциями и остальными акциями накапливается за период объявления плохих новостей;

3) асимметричная реакция гламурных акций и акций стоимости возникает в интервалах около даты объявления финансовых результатов.

Результаты

1. Средняя квартальная (рассчитанная за пять лет) сверхдоходность акций, для которых объявление финансовых результатов в данном квартале оказалось негативным сюрпризом, увеличивается по модулю от нижнего квинтиля (с наименьшим коэффициентом рыночная стоимость к балансовой) к верхнему (см. табл.2), т.е. для гламурных акций наблюдается более сильная негативная реакция на плохие новости-сюрпризы $(-7,32 \%)$, чем для акций стоимости (-3,57\%). Для положительных новостей-сюрпризов доходности между квинтилями изменяются U-образно, но вряд ли это можно считать закономерностью, к тому же разница несущественна: 6,32\% для гламурных акций и 5,44\% для акций стоимости. При точном соответствии реальных финансовых результатов ожидаемым наблюдается невысокая положительная доходность, примерно одинаковая для разных квинтилей (от 1,13 до 2,01\%). Это означает, что предсказуемая более низкая доходность для компаний с высоким коэффициентом «рыночная стоимость к балансовой» получается в результате объявления такими компаниями неожиданно плохих новостей несколько раз подряд. 
Таблица 2.

Реакция рынка на хорошие и плохие новости в зависимости от типа акций (\%)*

\begin{tabular}{|c|c|c|c|c|}
\hline Портфели акций & $\begin{array}{c}\text { Хорошая } \\
\text { новость } \\
(E S>0)\end{array}$ & $\begin{array}{c}\text { Нейтральная } \\
\text { новость } \\
(\mathrm{ES}=0)\end{array}$ & $\begin{array}{c}\text { Плохая } \\
\text { новость } \\
(\mathrm{ES}<0)\end{array}$ & Все новости \\
\hline $\begin{array}{c}\mathbf{1} \\
\text { (акции } \\
\text { стоимости, } \\
\text { низкий МВ) }\end{array}$ & $\begin{array}{c}-3,57 \\
(50,0)\end{array}$ & $\begin{array}{c}1,13 \\
(6,2)\end{array}$ & $\begin{array}{c}5,44 \\
(43,8)\end{array}$ & 0,66 \\
\hline 2 & $\begin{array}{c}-3,91 \\
(49,0)\end{array}$ & $\begin{array}{c}2,01 \\
(8,6)\end{array}$ & $\begin{array}{c}4,93 \\
(42,4)\end{array}$ & 0,35 \\
\hline 3 & $\begin{array}{c}-4,89 \\
(48,3)\end{array}$ & $\begin{array}{c}1,71 \\
(11,3)\end{array}$ & $\begin{array}{c}5,29 \\
(40,4)\end{array}$ & $-0,03$ \\
\hline 4 & $\begin{array}{c}-5,82 \\
(47,3) \\
\end{array}$ & $\begin{array}{c}1,54 \\
(15,2) \\
\end{array}$ & $\begin{array}{c}5,65 \\
(37,5) \\
\end{array}$ & $-0,40$ \\
\hline $\begin{array}{c}\mathbf{5} \\
\text { (гламурные } \\
\text { акции, } \\
\text { высокий MB) }\end{array}$ & $\begin{array}{c}-7,32 \\
(44,1)\end{array}$ & $\begin{array}{c}1,65 \\
(19,1)\end{array}$ & $\begin{array}{c}6,32 \\
(36,8)\end{array}$ & $-0,58$ \\
\hline Все портфели & $\begin{array}{c}-5,04 \\
(47,8) \\
\end{array}$ & $\begin{array}{c}1,63 \\
(12,0) \\
\end{array}$ & $\begin{array}{c}5,50 \\
(40,2) \\
\end{array}$ & $\begin{array}{c}0,00 \\
(100)\end{array}$ \\
\hline
\end{tabular}

Источник: данные взяты из исследования Skinner, D., and R. Sloan (2002), Earnings surprises, growth expectations and stock returns or Don't let an earnings torpedo sink your portfolio // Review of Accounting Studies.

* В ячейках приведена средняя квартальная сверхдоходность (Fullret) для портфелей акций, сформированных на основании отношения рыночной стоимости к балансовой (Market-to-Book ratio), и знак новостного шока (положительный, негативный и нулевой). В скобках указывается процентное соотношение новостей соответствующей категории (негативный сюрприз, позитивный или нейтральный) к общему количеству новостей, объявляемых рынку соответствующим типом акций.

В самом правом столбце таблицы мы также видим, что средняя сверхдоходность монотонно убывает с отметки $0,66 \%$ для акций стоимости до $-0,58 \%$ для гламурных акций. Этот на первый взгляд небольшой разрыв в сверхдоходностях превращается в 5,05\%-ный разрыв на интервале в год. Эта величина, в свою очередь, немногим меньше $8-10 \%$-ной разницы, которую получали другие исследователи, например Лаконишок и др. [Lakonishok et al., 1994] (здесь необходимо заметить, что в упомянутом исследовании разница рассчитывалась между крайними децилями акций, а не квинтилями, и выборка не ограничена требованием аналитического покрытия, что, безусловно, меняет результат).

Небезынтересный факт отображен также в последней строке таблицы: здесь мы видим, что на всей выборке акций реакция на плохие новости $(-5,04 \%)$ по силе (по модулю) примерно соответствует хорошим новостям (5,50\%), однако асимметрична относительно реакции на нейтральные новости $(1,63 \%)$. Авторы соотносят это обстоятельство с тем, что компании чаще объявляют плохие новости-сюрпризы рынку $(47,8 \%)$, чем хорошие $(40,2 \%)$. Причина этого, в свою очередь, - завышенные прогнозы аналитиков, которым присущ чрезмерный оптимизм, что фиксировалось эмпирически такими исследователями как Абарбанелл и Леви [Abarbanell and Lehavy, 2000]и Браун [Brown, 2001].

2. Авторы исследуют реакцию рынка (а именно сверхдоходность) на четырех различных интервалах: так называемых Fullret, Preret, Postret и Aret. Их соотношение и 
протяженность показана на рис. 3. Такое деление на интервалы позволяет понять, в какой именно момент возникает разница между сверхдоходностями разных типов акций и с чем соответственно она связана. Так, согласно исследованиям Скиннера [Skinner, 1997] и Соффера и др. [Soffer et al., 2000], более 75\% всех предварительных объявлений финансовых результатов заключено в промежутке 2 недели до и 2 недели после конца отчетного квартала; в числе этих объявлений находятся сообщения компаний о неожиданно плохих результатах, поскольку компании обычно стараются сообщать такие новости заранее. Таким образом, интервал Preret очищен по максимуму от объявлений, связанных с финансовыми результатами, a Postret, напротив, содержит в себе и само объявление, и предварительные сообщения компании, в то время как Aret заключает в себе лишь небольшой промежуток вокруг даты объявления (в аналогичных исследованиях, например Ла Порта и др. [La Porta et al., 1997], а также Бернард и др. [Bernard et al., 1997], часто изучается именно этот интервал).

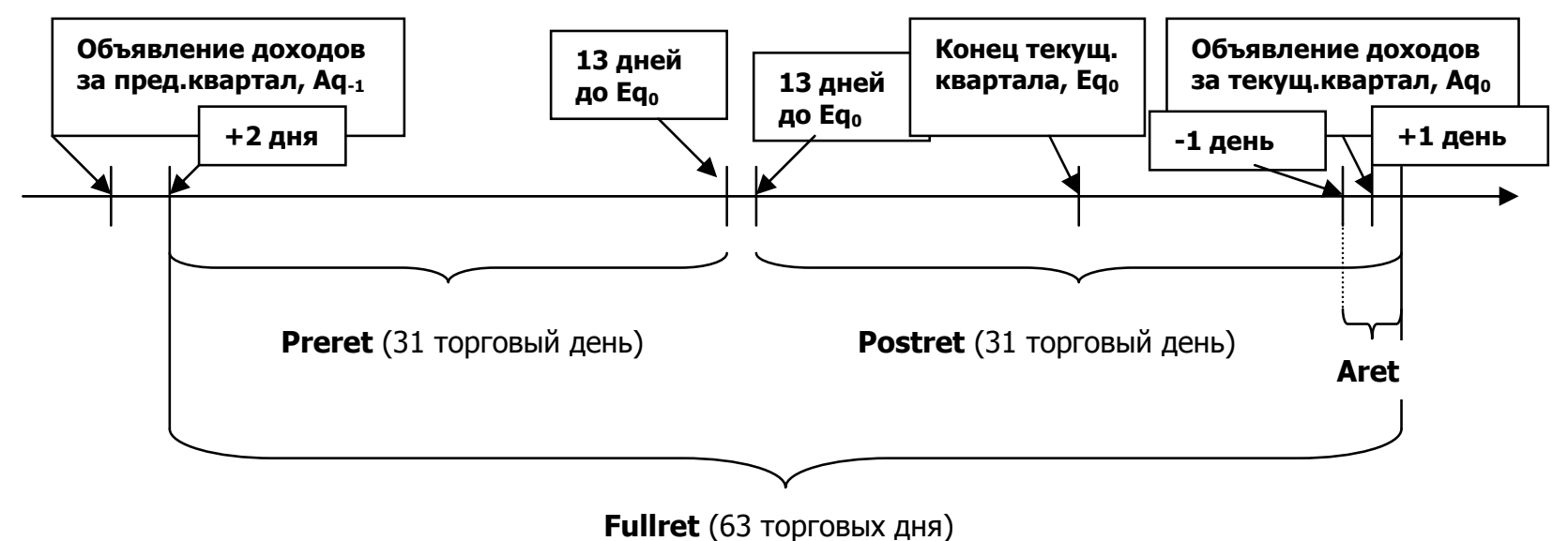

Рис. 3. Изучаемые интервалы: Fullret, Preret, Postret и Aret

Как и ожидалось, наихудшие результаты акций роста (в терминах доходности) сконцентрированы в 31-дневном интервале, предшествующем непосредственное объявление квартальных финансовых результатов компании (Postret). При этом в день официального объявления финансовых результатов (а именно на интервале Aret) наблюдается относительно небольшая реакция, и причина этому, как полагают авторы, - обыкновение менеджеров растущих компаний объявлять плохие новости заранее. Таким образом, большая часть реакции на объявляемые новости приходится на предшествующий объявлению период, и вызывается она предварительными сообщениями (и корректировками) менеджмента компаний, тогда как официальное объявление почти не содержит для рынка существенной и новой информации. В свою очередь, Конрад, Корнелл и Ландсман [Conrad, Cornell and Landsman, 2002], занимаясь вопросом доходности гламурных акций и акций стоимости, изучали сверхдоходность также крайних квинтилей, сформированных, однако, на основе коэффициента Р/Е, и на 20-дневном интервале, предшествующем объявлению квартальных финансовых результатов компании. Авторы не находят никакой существенной разницы между доходностями акций стоимости и гламурных акций, о чем и делают вывод. Однако здесь необходимо учитывать, что период, на котором изучается и рассчитывается сверхдоходность, не включает в себя те две недели до конца отчетного периода, на которые приходится большая часть предварительных объявлений менеджмента, на которые и реагирует в основном рынок. Вероятно, именно это стало причиной таких результатов.

3. Авторы выявляют асимметричную реакцию доходности акций роста на новости о финансовых результатах. На рис. 3 показана эмпирическая зависимость квартальной сверхдоходности от ошибки ожиданий инвесторов (степень неожиданности новости) отдельно для акций стоимости и акций роста. Ошибка ожидания (FE, Forecast error) 
рассчитывается как величина сюрприза, поделенная на цену акции на конец последнего месяца в отчетном квартале $\left(\mathrm{Eq}_{0}\right)$ :

$$
F E=\text { EarningsSurprise } / \operatorname{Pr} i c e\left(E q_{0}\right)=(\text { ActualEPS }- \text { MedianForecastEPS }) / \operatorname{Pr} i c e\left(E q_{0}\right) \text {. }
$$

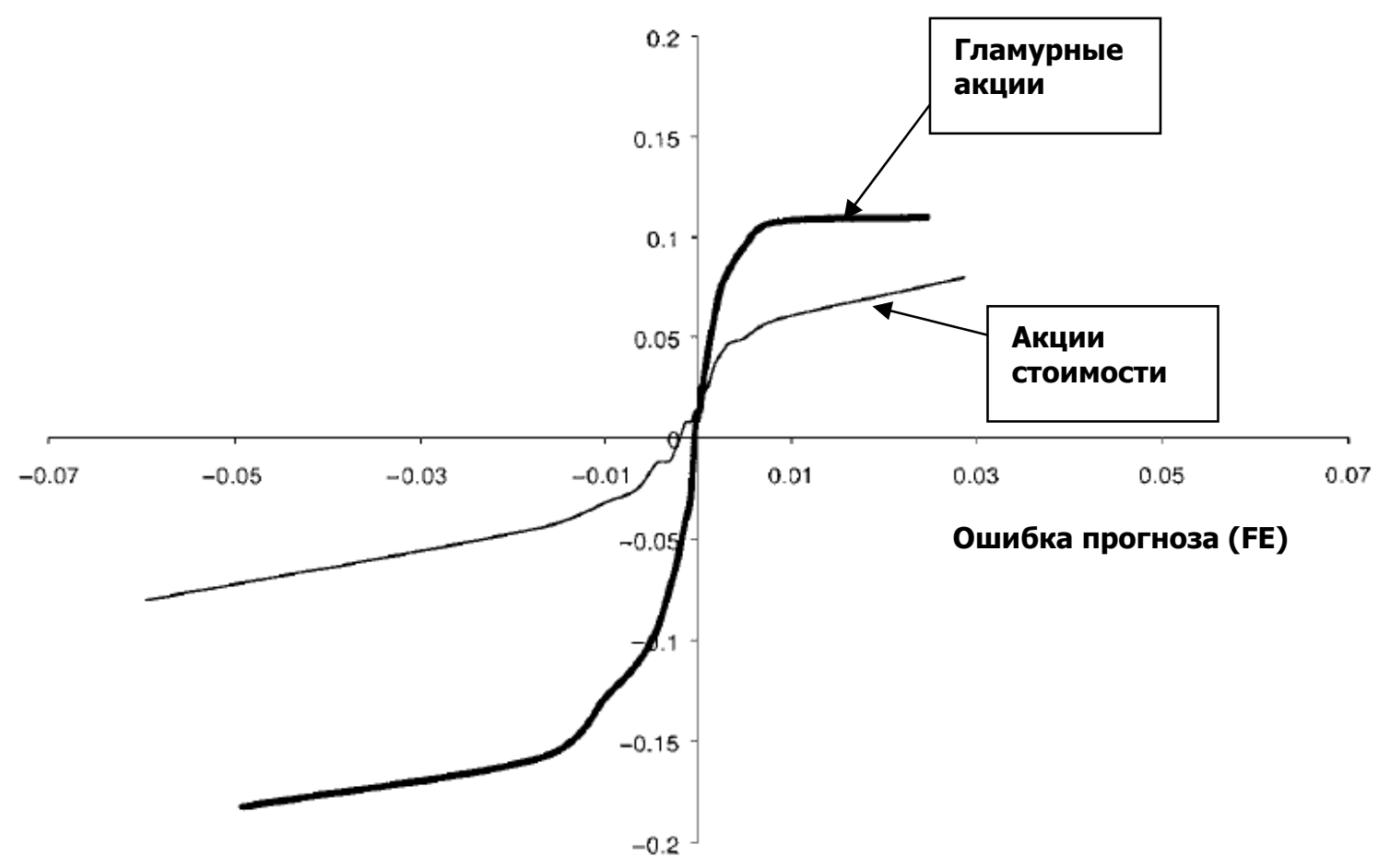

Рис. 4. Функции реакции рынка на новости-сюрпризы для гламурных акций и акций стоимости*

Источник: Skinner, D., and R. Sloan. Earnings surprises, growth expectations and stock returns or Don't let an earnings torpedo sink your portfolio. // Review of Accounting Studies, 2002.

* График отражает квартальную сверхдоходность для акций стоимости и гламурных акций, как функцию от величины ошибки прогноза доходов. Акции каждого типа были поделены на 20 портфелей в зависимости от величины ошибки прогноза; таким образом, точка отражает среднюю сверхдоходность каждого из 20 портфелей и соответствующую ему ошибку прогноза. Полученные таким образом точки соединены сглаживающей кривой.

Как мы видим, для акций стоимости эта зависимость симметрична - в случае и хороших, и плохих сюрпризов сверхдоходность одинаково увеличивается по модулю и достигает максимума немногим больше 5\% по абсолютной величине. Для акций роста эта зависимость имеет совсем иной характер: в случае хороших сюрпризов сверхдоходность резко растет и достигает максимума (чуть больше 10\%) при небольшой ошибке прогноза (т.е. акции роста переигрывают акции стоимости в случае хороших новостей). В случае плохих сюрпризов сверхдоходность асимметрично сильно падает и достигает примерно 17\%. График сверхдоходности гламурных акций в зависимости от степени неожиданности новости сильно напоминает функцию субъективного восприятия выигрышей и потерь Канемана и Тверски [Kahneman and Tversky, 1979]. Заметим, что компании роста объявляют по крайней мере не больше негативных новостей по сравнению с компаниями стоимости (см. табл.2), поэтому такая разница в сверхдоходностях не может быть списана на большее количество негативных новостей на счету компаний роста.

Авторы полагают, что это может объяснить упоминавшуюся выше «аномалию», согласно которой, гламурные акции переигрывают акции стоимости по доходности за 5 лет 
после формирования портфеля. Они делают поправку на асимметричную реакцию гламурных акций на плохие и хорошие новости, в результате чего разница между гламурными акциями и остальными исчезает. То есть худшие показатели (а именно доходность) гламурных акций вызваны ошибками инвесторов в ожиданиях относительно будущих доходов компании. Таким образом, исследование подтверждает поведенческое объяснение этого феномена: инвесторы формируют слишком оптимистичные ожидания относительно перспектив гламурных акций, что и приводит в результате к пониженной доходности (см., в частности, Лаконишок и др. [Lakonishok, Shleifer and Vishny, 1994]). Другие два объяснения, предложенные экономистами, а именно: 1) меньшая рисковость гламурных акций (Фама и Френч [Fama and French, 1992]) и 2) определенные методологические проблемы расчета долгосрочной доходности, создающие иллюзию худших результатов гламурных акций (Фама [Fama, 1998] и Котари и др. [Kothari, Sabino and Zach, 1999]), не согласуются с результатами данного исследования.

\section{5. Фактор № 4. Тип инвесторов компании - институциональный и индивидуальный}

Если исходить из неоклассической модели стоимости фирмы (где стоимость складывается из приведенных будущих денежных потоков), то доходность акций компании должна реагировать на изменения (шоки) ожидаемых денежных потоков (т.е. на новости о денежных потоках) и/или на изменения (шоки) ставок дисконтирования (т.е. на новости об ожидаемой доходности). Однако многие эмпирические исследования указывают на то, что цена акций отдельной компании недостаточно реагирует на новости о денежных потоках. События, которые априори содержат информацию, относящуюся к денежным потокам, такие как объявление финансовых результатов и решения о начале и прекращении выплаты дивидендов, сопровождаются дрифтом цен акций в том же направлении, что и первоначальная доходность после объявления (например, Микаэли и др. [Michaely et al., 1995], Бернард и Томас [Bernard and Thomas, 1989] и др.). Причем Коэн, Гомперс и Виолтеенахо [Cohen, Gompers and Vuolteenaho, 2002] обнаружили, что институциональные инвесторы знают о данном эффекте (так называемый эффект недостаточной реакции underreaction) и используют его с выгодой для себя. Так, институциональные инвесторы в ответ на объявление хороших новостей о денежных потоках покупают акции этой компании у индивидуальных инвесторов и продают акции, если новости о денежных потоках плохие (наиболее сильная негативная реакция наблюдается на плохие новости крупных компаний). Согласно векторной авторегрессии, новости о денежных потоках приводят к покупке институтами примерно 2\% обыкновенных акций (такой объем торгов экономически значим). Авторы указывают, что институциональные инвесторы реагируют именно на новости о денежных потоках - объявление таких новостей их активизирует. Если же цена сильно повышается (или понижается) в отсутствие выпуска новостей о денежных потоках, то стратегия институционального инвестора меняется на противоположную: он продает акции индивидуальным инвесторам в ответ на повышение цены и покупает соответственно в ответ на понижение цены (объем продажи при изменении цены на 25\% составляет $5 \%$ от общего количества обыкновенных акций). Авторы приходят к выводу, что институциональные инвесторы действительно понимают процесс формирования доходностей на рынке, включая действие эффектов чрезмерной (overreaction) и недостаточной реакции (underreaction), и используют свои знания в инвестиционных решениях с выгодой для себя. Однако, замечают авторы, эта группа инвесторов также использует в своих инвестиционных стратегиях определенные эвристики, привязанные к ожидаемым доходностям.

Таким образом, сила эффекта «недостаточной реакции» (underreaction) зависит от структуры инвесторов: можно предположить, что если у компании достаточное количество институциональных инвесторов (или объемы их трейдов велики), то эффект недостаточной реакции будет не таким сильным, как если бы компания не привлекала институциональных инвесторов. В частности, институциональные инвесторы обходят стороной акции компаний 
с маленькой капитализацией (в связи с экзогенными ограничениями на торги такими акциями), в результате такие акции демонстрируют наиболее сильный эффект недостаточной реакции.

Экхольм [Ekholm, 2002] подтверждает на выборке финских компаний и регистра владельцев акциями в Финляндии результаты Коэна, Гомперса и Вуолтеенахо [Cohen, Gompers and Vuolteenaho, 2002]: большинство инвесторов чаще всего продают акции компаний после объявления неожиданно хороших новостей о ее доходах и покупают - после плохих. Также они имеют тенденцию покупать акции после раскрытия новой финансовой информации. Крупные инвесторы, напротив, демонстрируют поведение, прямо противоположное поведению большинства.

Аналогичные результаты получил Ли [Lee, 1992], анализируя объем трейдов после объявлений финансовых результатов. На этот раз исследование проводилось на данных американского рынка. Автор установил, что после неожиданных положительных новостей о финансовых результатах увеличивается доля больших по объему трейдов на покупку, а после плохих - возрастает доля таких трейдов на продажу; количество мелких транзакций возрастает вне зависимости от выпуска новостей.

\section{6. Фактор № 5. Тип события}

До этого момента мы ссылались на исследования, которые в качестве новостей брали объявления о финансовых результатах. Эти новости очень значимы для инвесторов, однако есть и другие важные новости, на которые инвесторы реагируют не менее сильно. Это, в частности, новости об инвестиционной деятельности компании - проведение слияния или поглощения, изменение структуры капитала, связанное с эмиссией долговых обязательств, вторичным выпуском капитала и т.д.; новости о финансовой деятельности - например, изменение дивидендной политики; и, наконец, новости об операционной деятельности. Оказалось, что новости в зависимости от типа сообщаемого события оказывают определенное влияние на рыночную стоимость компании. Первым это обнаружил Ролл [Roll, 1988], который исследовал реакцию рынка на публичные новости на уровне отдельных компаний. До него такие исследования проводились на более общем уровне, т.е. на агрегированных данных, и делался вывод, что хоть новости и вызывают движение цен на рынке, однако зависимость довольно слабая (Шверт [Schwert, 1981] и Митчелл и Мулерин [Mitchell and Mulherin, 1994]). В свою очередь, Ролл [Roll, 1988] установил, что если сгруппировать новости в зависимости от типа события, то можно получить определенные закономерности поведения доходности. С этого момента подобные исследования стали очень популярны, и на сегодняшний день по каждому событию можно найти не одно, а целый ряд исследований, в которых изучается реакция рынка на данное событие - в краткосрочном периоде, долгосрочном, на разных выборках и разных рынках капитала. В число изучаемых событий наиболее часто попадают события, имеющие сигнальную функцию (например, выкупы, IPO, дивидендная политика и т.д.), а также регулярные выпуски новостей. Результаты эмпирических исследований, изучающих поведение доходности в зависимости от различных типов событий, вызвавших изменение доходности, можно свести в следующую таблицу. 
Реакция рынка на новости в зависимости от типа события: слишком сильная (overreaction) и недостаточная реакция (underreaction)

\begin{tabular}{|c|c|}
\hline Тип события & Исследование и результаты: \\
\hline \multicolumn{2}{|c|}{ Сигнализирующие события } \\
\hline $\begin{array}{l}\text { 1. Дивидендная } \\
\text { политика }\end{array}$ & $\begin{array}{l}\text { Микаэли и др. [Michaely et al., 1995] изучали инициирование } \\
\text { дивидендных выплат и отмену и обнаружили недостаточную } \\
\text { реакцию }\end{array}$ \\
\hline 2. Дробление акций & $\begin{array}{l}\text { Икенберри и Рамнат [Ikenberry and Ramnath, 2002] и Икенберри } \\
\text { и др. [Ikenberry et al., 1996] обнаружили недостаточную реакцию }\end{array}$ \\
\hline $\begin{array}{l}\text { 3. Изменения } \\
\text { структуры капитала }\end{array}$ & $\begin{array}{l}\text { Инвесторы, похоже, склонны медленно реагировать на } \\
\text { изменения структуры капитала, в частности, исследователи } \\
\text { фиксируют дрифт после следующих событий: } \\
\text { • Тендерные предложения (Икенберри и др. [Ikenberry et } \\
\text { al., 1995]). } \\
\text { • } \\
\text { Выкупы акций на открытом рынке (Икенберри и др. } \\
\text { [Ikenberry et al., 1995]). } \\
\text { Вторичные paзмещения coбственного капитала (Лугран и } \\
\text { Риттер [Loughran and Ritter, 1995], и Спайс и Аффлек- } \\
\text { Грейвз [Spiess and Affleck-Graves, 1995]). } \\
\text { • Pacпределение венчурного капитала (Гомперс и Лернер } \\
\text { [Gompers and Lerner, 1998]) }\end{array}$ \\
\hline $\begin{array}{l}\text { 4. Слияния и } \\
\text { поглощения }\end{array}$ & $\begin{array}{l}\text { Доходность компании-захватчика демонстрирует возвращение к } \\
\text { среднему, или эффект слишком сильной реакции (Агравал и др. } \\
\text { [Agrawal et al., 1992]). } \\
\text { В случае борьбы за контроль над компанией также наблюдается } \\
\text { возвращение к среднему (Икенберри и Лаконишок [Ikenberry and } \\
\text { Lakonishok, 1993]) }\end{array}$ \\
\hline $\begin{array}{l}\text { 5. Первичное } \\
\text { размещение акций } \\
\text { (IPO) }\end{array}$ & $\begin{array}{l}\text { Масса различных типов поведения доходности, в зависимости } \\
\text { от временного горизонта: первоначальная недооцененность и } \\
\text { долгосрочная неэффективность (Риттер [Ritter, 1991]) }\end{array}$ \\
\hline \multicolumn{2}{|c|}{ Регулярные выпуски новостей } \\
\hline $\begin{array}{l}\text { 1. Объявление } \\
\text { финансовых } \\
\text { результатов }\end{array}$ & $\begin{array}{l}\text { Бернард и Томас [Bernard and Thomas, 1989] и другие выявили } \\
\text { дрифт после неожиданных новостей о доходах (сюрпризов), } \\
\text { продолжающийся до } 12 \text { месяцев с даты выпуска новости }\end{array}$ \\
\hline $\begin{array}{l}\text { 2. Рекоммендации } \\
\text { аналитиков }\end{array}$ & $\begin{array}{l}\text { Микаэли и Вомак [Michaely and Womack, 1999] обнаружили, что } \\
\text { рынок реагирует на изменения рекомендаций аналитиков с } \\
\text { запаздыванием. Вомак [Womack, 1996] получил асимметричную } \\
\text { реакцию на изменения рекомендаций аналитиков (и также с } \\
\text { лагом) }\end{array}$ \\
\hline
\end{tabular}

В данной таблице рассмотрен характер реакции на события различного типа - т.е. показано, насколько быстро информация, поступающая на рынок с новостью, учитывается в цене акций соответствующей компании. На эффективном рынке вся релевантная информация о компании должна тут же в полной мере отражаться в цене. В реальности этого не происходит:

-инвесторы либо реагируют с опозданием, т.е. цена акции начинает постепенно изменяться в соответствующем направлении и достигает адекватного уровня лишь через некоторый промежуток времени, - такая модель реакции называется «недостаточная Выпуск \#1(9), 2009 
реакция» (underreaction), или «дрифт» (drift);

-либо инвесторы реагируют слишком сильно, т.е. сразу же после выхода новости на рынок цена акции изменяется неадекватно сильно, и через некоторое время происходит корректировка цены, или так называемое возвращение к среднему, - такая модель реакции получила название «слишком сильная реакция» (overreaction).

Исследователи также изучают, как именно изменяется поведение доходности в связи с объявлением того или иного события - в количественном выражении. Нашей целью в рамках данной работы не является составление сводной таблицы по всем событиям с указанием, сколько процентов сверхдоходности «зарабатывают» акции компании после того или иного события. Однако в качестве примера мы приведем результаты исследования Притамани и Сингала [Pritamani and Singal, 2001], которое выгодно отличается подходом к изучению данного вопроса. Особенность указанного исследования заключается в следующем.

При всем разнообразии и многочисленности работ, изучающих поведение доходности акций после объявления новой информации о компании, все они апроксимируют поступление информационного сигнала одним параметром: либо существенным ростом объема, либо сильным изменением цены, либо фактом публичного объявления. Притамани и Сингал полагают, что, изучая эти показатели по отдельности, невозможно получить истинное представление о влиянии информационного сигнала на доходность акций, поскольку информационный сигнал задается набором важных характеристик. Авторы указывают три главные характеристики информационного сигнала: величину, точность и распространение. Таким образом, каждый из вышеперечисленных прокси передает только одну из этих трех характеристик: изменение цены отражает силу сигнала, изменение объема - точность, и факт публичного объявления - уровень распространения информации. Поэтому авторы предлагают (и считают единственно правильным) использовать три прокси одновременно для изучения предсказуемости доходности. Этот подход они и реализуют в своем исследовании.

Изучая доходности акций в зависимости от типа объявляемого события, Притамани и Сингал выделяют семь типов событий:

а) объявление фактических доходов менеджментом компании;

б) прогноз доходов менеджментом компании;

в) рекомендации аналитиков: рекомендации аналитиков по ценным бумагам и информация о кредитных рейтингах, выпускаемая рейтинговыми агентствами;

г) события, относящиеся к структуре капитала: дивиденды, выкупы акций, соотношение собственного капитала и долга и т.д.;

д) события, связанные с реструктуризацией: слияния, поглощения, продажа активов, найм и увольнение высшего управляющего состава;

е) общая операционная информация о компании: продажи, информация о продукции, деловые контракты и т.д.;

ж) разнообразная информация: юридические и законодательные вопросы, конфликты с работниками.

Авторы отдельно изучают положительные события разных типов (т.е. типы событий, которые сопровождались сильным ростом цены) и отрицательные (типы событий, которые сопровождались сильным падением цены).

В подвыборке положительных событий авторы выделяют события типов а (объявление фактических доходов менеджментом компании), б (прогноз доходов менеджментом компании) и в (рекомендации аналитиков), для которых наблюдается сильная и систематическая недостаточная реакция (underreaction) на интервале 20 дней после события. Перечисленные типы событий сопровождаются статистически значимыми сверхдоходностями на 20-дневном интервале вдобавок к первоначальной реакции в день события, что и указывает нам на наличие дрифта. Что касается реакции рынка на остальные типы событий, сопровождаемых ростом объема торгов, то здесь не наблюдается 
аномального поведения доходности. В подвыборке с не менявшимся объемом торгов также не выявлено аномального поведения доходности, за исключением событий, связанных со структурой капитала (тип г): здесь наблюдается существенный эффект слишком сильной реакции.

В случае с негативными событиями статистически значимая сверхдоходность с эффектом недостаточной реакции наблюдается только при объявлении менеджментом доходов компании, прогнозов доходов и выпуском рекомендаций аналитиков (типы а, б, в) - аналогично выборке с положительными событиями. В случае общих операционных событий (тип е), сопровождаемых увеличением объема торгов, напротив, наблюдается чрезмерная реакция.

Таблица 4.

Доходность в зависимости от типа объявленного события, изменения цены и объема*

\begin{tabular}{|c|c|c|c|c|c|}
\hline \multirow{3}{*}{ Тип события } & \multirow{3}{*}{ 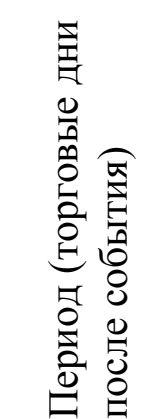 } & \multicolumn{4}{|c|}{$\begin{array}{l}\text { Сверхдоходность в день события и за период } \\
\text { с 1-го по 20-й день после события }\end{array}$} \\
\hline & & \multicolumn{2}{|c|}{$\begin{array}{l}\text { Сильный рост цены } \\
\text { (положительное } \\
\text { событие) }\end{array}$} & \multicolumn{2}{|c|}{ 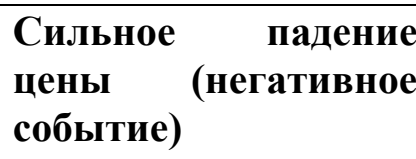 } \\
\hline & & $\begin{array}{l}\text { Объем } \\
\text { торгов } \\
\text { вырос, \% }\end{array}$ & $\begin{array}{l}\text { Объем } \\
\text { не изме- } \\
\text { нился, \% }\end{array}$ & $\begin{array}{l}\text { Объем } \\
\text { торгов } \\
\text { вырос, \% }\end{array}$ & $\begin{array}{l}\text { Объем } \\
\text { не изме- } \\
\text { нился, \% }\end{array}$ \\
\hline \multirow{2}{*}{$\begin{array}{l}\text { a) объявление } \\
\text { доходов } \\
\text { менеджментом }\end{array}$} & 0 & 8,03 & 6,75 & $-9,79$ & $-6,32$ \\
\hline & {$[+1 ;+20]$} & 3,44 & 6,75 & $-2,60$ & $-1,93$ \\
\hline \multirow{2}{*}{$\begin{array}{l}\text { б) прогноз доходов } \\
\text { менеджментом }\end{array}$} & 0 & 8,65 & 7,41 & $-11,20$ & $-6,59$ \\
\hline & {$[+1 ;+20]$} & 4,16 & & $-1,96$ & \\
\hline \multirow{2}{*}{$\begin{array}{l}\text { в) рекомендации } \\
\text { аналитиков }\end{array}$} & 0 & 8,32 & 6,59 & $-7,76$ & $-5,56$ \\
\hline & {$[+1 ;+20]$} & 3,59 & & $-2,39$ & $-3,01$ \\
\hline \multirow{2}{*}{$\begin{array}{l}\text { г) структура } \\
\text { капитала }\end{array}$} & 0 & 6,69 & 5,41 & $-8,21$ & $-5,48$ \\
\hline & {$[+1 ;+20]$} & & $-3,74$ & & \\
\hline \multirow[t]{2}{*}{ д) реструктуризация } & 0 & 12,76 & 6,05 & $-10,02$ & $-5,76$ \\
\hline & {$[+1 ;+20]$} & & & & \\
\hline \multirow{2}{*}{$\begin{array}{l}\text { e) общая } \\
\text { операционная } \\
\text { информация } \\
\end{array}$} & 0 & 7,10 & 6,47 & $-9,67$ & $-5,78$ \\
\hline & {$[+1 ;+20]$} & & & 1,98 & \\
\hline \multirow{2}{*}{$\begin{array}{l}\text { ж) другая } \\
\text { информация }\end{array}$} & 0 & 7,77 & 4,43 & $-7,45$ & $-8,05$ \\
\hline & {$[+1 ;+20]$} & & & & \\
\hline
\end{tabular}

Источник: Таблица составлена по данным исследования Pritamani, M., and V. Singal. Return predictability following large price changes and information releases // Journal of Banking and Finance, 2001.

*B таблице указаны только статистически значимые сверхдоходности, пустые клетки означают, что сверхдоходности в этих случаях не являются статистически значимыми. Выборка: акции всех компаний, торгуемые на NYSE и AMEX за период 1990-1992 годов)

В годовом выражении сверхдоходность для событий типа а, б и в составляет порядка $40 \%$ в случае положительных событий и $-25 \%$ - в случае негативных.

Таким образом, тип события, о котором сообщается в новости, также оказывает влияние на рыночную стоимость компании. Так, тип события определяет, во-первых, характер реакции рынка, т.е. какая реакция будет наблюдаться - недостаточная или Выпуск \#1(9), 2009 
слишком сильная; во-вторых, силу реакции в выражении сверхдоходности.

\section{7. Фактор № 6. Степень распространенности новости}

Как уже говорилось выше, одной из важных характеристик информационного сигнала, по мнению Притамани и Сингала [Pritamani and Singal, 2001], является уровень распространения информации. Этот параметр, наряду с точностью и силой информационного сигнала, определяет поведение доходности, инициируемое данным сигналом. Хонг, Лим и Штайн [Hong, Lim and Stein, 2000] предположили, что чем медленнее распространяется информация, тем медленнее реагируют цены акций соответствующих компаний или тем сильнее проявляется эффект недостаточной реакции, о котором говорилось выше. В качестве прокси для уровня распространения информации исследователи предложили: 1) размер компании, поскольку для более мелких компаний информация распространяется медленнее (однако авторы сами признают определенные недостатки такого прокси) и 2) «аналитическое покрытие» акций компании. Во втором случае предполагается, что чем меньше внимания аналитиков привлекают к себе акции компании, тем медленнее распространяется информация об этих акциях. Аналитическое покрытие определялось на ежемесячной основе, как количество аналитиков, которые опубликовали свои оценки будущих финансовых результатов компании. Выборка включает в себя акции NYSE, AMEX и NASDAQ и охватывает период с 1976-го по 1996 год. Регрессионный анализ подтверждает гипотезу авторов для обеих прокси. Нам более интересен вывод относительно аналитического покрытия: чем менее интенсивно компания обозревается аналитиками, тем медленнее рынок реагирует на объявляемые компанией события и тем более сильный наблюдается дрифт. Это, безусловно, связано с чрезвычайно важной ролью аналитиков в распространении финансовой информации на рынке.

Аналогично Притамани и Сингал [Pritamani and Singal, 2001] приходят к выводу, что факт публичного объявления является необходимым условием для продолжения движения цены в первоначальном направлении (заметим, что факт публичного объявления в рассматриваемом исследовании является мерой высокого уровня распространения информации). То есть сильное изменение цены, с которым не связано никакого события (по крайней мере, не было найдено в популярных финансовых источниках), не сопровождается повышенной доходностью, как в случае изменений цен, связанных с событиями. Таким образом, заключают авторы, предсказуемость доходностей выше в случае публичных объявлений.

Этой же проблемой занимался Чан [Chan, 2003]. Он также отдельно исследовал поведение доходностей акций, по которым были объявлены новости, и акций, стоимость которых изменялась без объявления новостей. Автор выявил, что акции, о которых были опубликованы новости, демонстрируют дрифт, в отличие от акций, о которых новостей не было, что согласуется с результатами исследования Притамани и Сингала [Pritamani and Singal, 2001]. В частности, акции, сопровождаемые плохими новостями, демонстрируют негативный дрифт продолжительностью до 12 месяцев. В случае с акциями с хорошими публичными новостями наблюдается меньший дрифт. Кроме того, цены акций, о которых не публиковалось никаких новостей в месяц формирования портфеля, возвращались к среднему значению в следующий месяц. Это подтверждает мнение о том, что инвесторы слишком сильно реагируют на несущественную информацию.

Полученные данные о различных реакциях рынка на наличие и отсутствие новостей, в принципе, согласуются с теоретическими поведенческими моделями реакции рынка на новости, а именно Дэниэла, Хиршляйфера и Субраманиама [Daniel, Hirshleifer and Subrahmanyam, 1998], Барбериса, Шляйфера и Вишны [Barberis, Shleifer and Vishny, 1998], a также Хонга и Штайна [Hong and Stein, 1999].

Выявленные эффекты уменьшаются (хотя и остаются), если очистить выборку от акций с низкой ценой. То есть эффекты сильнее для «дешевых» акций - акций, для которых 
характерна меньшая ликвидность. Возможное объяснение этому - более медленная реакция отдельных инвесторов на информацию в совокупности с существенными транзакционными издержками, которые не позволяют арбитражерам сократить этот разрыв между поступлением информации и реакцией цены. Тот факт, что дрифт в большинстве случаев возникает после низких доходностей, говорит в пользу такого объяснения: так как короткие продажи акций являются более дорогостоящей транзакцией по сравнению с покупкой, то недостаточная реакция (и дрифт как результат) проявляется именно в ситуации плохих новостей. Автор также показывает, что самые сильные дрифты после плохих событий возникают в отсутствии объявления доходов и наблюдаются в течение следующих месяцев.

Результаты согласуются с двумя давно известными среди практиков идеями: 1) инвесторы слишком медленно реагируют на достоверную информацию, вызывая тем самым дрифт, и 2) инвесторы слишком сильно реагируют на ценовые шоки, что приводит к значительному повышению объемов торгов и волатильности и завершается возвращением цены к среднему.

\section{Часть 2. Интегральный анализ факторов, или Модель влияния новостей на рыночную стоимость компании}

Критический анализ исследований различных аспектов влияния корпоративных новостей на рыночную стоимость компаний, который был представлен вниманию читателя выше, позволяет нам выделить основополагающие блоки в цепочке «объявление новости рыночная стоимость компании». Эти блоки и есть те важные факторы, которые определяют, как в итоге изменится рыночная стоимость компании после объявления той или иной новости. Мы выделяем четыре блока факторов, определяющих характер влияния новости на рыночную стоимость компании:

1) параметры объявляемой новости, т.е. что поступает на рынок;

2) каналы распространения новости, т.е. как новость поступает на рынок;

3) контекст восприятия инвесторами новости, т.е. где, в каком контекстовом окружении оказывается и анализируется новость;

4) тип инвесторов, т.е. кто получает и использует новость в инвестиционных решениях.

Для удобства восприятия мы располагаем блоки факторов в виде линейной последовательности, однако обращаем ваше внимание, что это не означает, что причинноследственные связи выстроены так же линейно: в разных случаях связи между блоками могут образовываться в иной последовательности или протекать параллельно.

Рис. 5. Модель влияния факторов на рыночную стоимость компании при объявлении корпоративных новостей 
Отдельно стоит отметить, что изменение рыночной стоимости компании не является простой суммой влияния каждого фактора. Безусловно, это естественное желание получить некую формулу, по которой можно точно посчитать, насколько вырастет или упадет стоимость компании при объявлении той или иной новости. Но по всей видимости, это утопия. Можно построить регрессию, в которую в качестве объясняющих переменных включить все перечисленные на схеме факторы, однако это будет неэффективно - как с точки зрения эконометрики, так и экономического смысла. В частности, подобная формула будет давать сильные погрешности, поскольку во-первых, коэффициенты в регрессионном уравнении оцениваются по общей выборке, усредняя специфику каждой компании, а каждая конкретная компания находится в конкретной специфической ситуации; во-вторых, факторы действуют не аддитивно, а вступая друг с другом в различные неформализуемые связи, которые модифицируют итоговую реакцию рынка (прибегнув к помощи комбинаторики, можно наглядно убедиться, что просчитать, оценить влияние на стоимость всех возможных комбинаций факторов невозможно); в-третьих, количество включаемых объясняющих переменных неизбежно ухудшает качество регрессии в связи с мультиколлинеарностью.

В связи с вышесказанным мы решили пойти по другому пути и разработать методику, которая позволит качественно оценить, как та или иная новость повлияет на динамику рыночной стоимости. Но прежде мы попытаемся обосновать ценность такого подхода, которая, возможно, представляется сомнительной в глазах приверженцев количественных методов и просто скептиков.

Рынок сложно описать математически, однако его все же можно понять, несмотря на то что инвесторы не являются рациональными. Причинно-следственные связи, существующие на рынке, сложны, многочисленны, но достаточно естественны и логичны, если учитывать человеческую психологию. Так, например, вполне естественно предположить, что прогнозы аналитиков особенно сильно влияют на решения инвесторов, когда тем сложно оценить ситуацию самостоятельно, т.е. когда новость не несет достаточно информации, позволяющей оценить стоимость компании. Далее, основываясь на этом общем понимании, мы можем выделить более частные и конкретные факторы, которые будут увеличивать влияние прогнозов аналитиков на изменение рыночной стоимости, например, использование высоких технологий, высокие затраты на исследования и разработки, убыточность в текущем периоде, размер компании, низкая доля постоянных доходов в общем входящем денежном потоке и т.д. Значимость этих параметров подтверждают данные эмпирического исследования Амира, Лева и Суджанниса [Amir, Lev and Sougiannis, 1999]. Авторы количественно показали, что факторы, усложняющие инвесторам самостоятельную оценку новости, повышают влияние аналитиков на реакцию стоимости компании на эту новость. В частности, авторы получили такие данные:

- использование компанией высоких технологий повышает вклад аналитиков ${ }^{12}$ до $36 \%$ против $28 \%$ для нетехнологичных компаний и 2,4\% для регулируемых компаний;

- высокие затраты на исследования и разработки - вклад аналитиков составляет $20 \%$ против $10 \%$ для компаний с низким показателем таких затрат;

- убыточность в текущем периоде - 40\% против 11\% для прибыльных компаний;

- и некоторые другие.

Как мы видим на примере этой простой логической цепочки, значимыми факторами могут быть очень многие параметры компании и ее окружающей среды. При этом значимость каждого из этих факторов не есть фиксированная величина - она может меняться со временем. Фактор может приобретать сильное значение в восприятии инвесторов и существенно определять реакцию рынка на новость, а может терять свою

12 Вклад, выраженный в процентах, означает процентное увеличение показателя $\mathrm{R}^{2}$ при добавлении в регрессионное уравнение информации, содержащейся в прогнозах аналитиков. 
значимость, и тогда на первый план выступают другие факторы.

Руководство каждой отдельной компании лучше знает и лучше может оценить, какой фактор в тот или иной период времени будет сильнее влиять на поведение инвесторов в отношении акций компании. Например, для некоторых российских компаний наиболее значимы (т.е. наиболее сильно сказываются на движении котировок акций) действия основных конкурентов, публикация финансовых результатов и прогнозы аналитиков; для других эти параметры оказываются незначимыми, тогда как важными становятся приобретения и слияния (в частности, в рамках стратегии географической экспансии), а также изменения в структуре капитала; а для третьих особое значение приобретают дивидендные выплаты. Даже в реакции рынка на публикацию финансовой отчетности отдельной компании могут быть нюансы: инвесторы могут несущественно реагировать на финансовую отчетность, составленную в соответствии с российскими стандартами бухгалтерского учета, но сильно реагировать на финансовую отчетность, составленную в соответствии с ГААП (общепринятыми стандартами учета) ${ }^{13}$. Кроме того, важность факторов может падать или возрастать в зависимости от контекстных факторов (блок 3). Стабильные дивидендные выплаты могут стать значимым фактором для инвесторов, повышающим привлекательность компании и ее рыночную стоимость, во время общего рыночного спада, тогда как в хорошие времена инвесторы могут предпочитать компании роста, не платящие дивиденды [Baker and Wurgler, 2004a, 2004b]. Для выяснения этого требуется анализ структуры инвесторов компании и их предпочтений.

Приведем еще один пример того, как влияет контекст (а именно состояние фондового рынка) на поведение инвесторов. Так, на примере российского рынка мы видим, что в период бурного роста рынка инвесторов не столь сильно интересует показатель выручки. В этом случае инвесторы не обращают особого внимания на соотношение реальной выручки и ее прогноза и не реагируют столь эмоционально на «сюрприз доходов». Такая реакция со стороны инвесторов вполне естественна: при росте выручки на $20-30 \%$ в год ошибка в прогнозе на 5\% воспринимается как нечто несущественное. Фокус внимания рынка скорее будет сосредоточен на показателях чистой прибыли, или EBITDA ${ }^{14}$. Также важно учитывать, что максимальное влияние состояние рынка оказывает в своих экстремальных значениях (как и многие другие индикаторы) - в период бурного роста или кризиса. Находясь в среднем, «уравновешенном» состоянии, рынок становится не столь важным фактором, и на первый план выступают другие показатели. Что будет тем первостепенным фактором, который определит движение рыночной стоимости компании, зависит от индивидуальных особенностей компании.

Эти и многие другие примеры, которые можно приводить сколь угодно долго, и есть пресловутая специфика компании. Именно поэтому мы предлагаем определять влияние новости о событиях компании не на основе регрессионного уравнения или любой другой математической формулы, а на основе пошагового осмысленного анализа, который учитывает индивидуальную специфику компании и общие характерные зависимости, выявленные эмпирическими исследованиями и изложенные в первой части статьи.

Итак, предлагаемая нами методика анализа влияния новости на рыночную стоимость компании состоит из следующих шагов:

1-й шаг: Определить, как воспримут инвесторы новость - как хорошую или как плохую.

\footnotetext{
13 Все приведенные выше примеры - это неопубликованные результаты эмпирического исследования, выполненного магистрами экономического факультета МГУ, кафедры «Финансы и кредит» под руководством Анны Солодухиной в рамках курса «Поведенческий подход в финансах». Авторы выражают благодарность студентам: Елене Алексеенко, Марине Бобровской, Кириллу Билюшову, Наталье Вроцкой, Андрею Землянову, Сергею Исакову, Святославу Карчевскому, Вениамину Липскому, Лидии Михайловой, Ирине Оляевой, Кириллу Рогачеву, Александру Сухачеву, Екатерине Шипиловой.

14 Такую ситуацию мы наблюдаем на примере компании «Лебедянский» на протяжении 2006-го - первой половины 2008 года.
}

Выпуск \#1(9), 2009

() Электронный журнал Корпоративные Финансы, 2009 
Для этого нужно пропустить новость через 4 блока факторов модели, задействуя для анализа релевантные факторы.

2-й шаг: Зная «знак» новости, оценить реакцию рынка на эту новость.

Для этого мы заново проходим все 4 блока модели, анализируя интегрированное влияние всех значимых для данной компании факторов.

3-й шаг: Скорректировать подачу новости с целью максимально улучшить реакцию рынка.

На первом шаге мы определяем, как будет воспринята инвесторами новость, которую собираемся сообщить рынку. Для этого мы можем использовать следующие методы: 1) мы можем обратиться к историческим данным и посмотреть, как инвесторы прежде реагировали на подобные новости (допустим, это касается политики в области слияний и поглощений, и компания совершила уже целый ряд таких сделок); 2) мы можем сравнить показатели, о которых собираемся сообщить рынку (например, показатели планируемой сделки), с ожидаемыми инвесторами. В первом случае мы должны понимать, что такой метод не лишен недостатков: на реакцию рынка в прошедших периодах (а значит, и на оценку «знака» новости) могло влиять много других, в особенности контекстных, факторов, которые, возможно, в текущем периоде никак себя не проявят. Может поменяться структура инвесторов, или их предпочтения, или состояние фондового рынка, и сделка, которая в таких условиях была оценена рынком положительно, в новых условиях будет оценена негативно. Очистить новость от влияния прошлого контекста и «наложить» на нее влияние нового - это сложная задача, которая требует много усилий, но не гарантирует результата. На наш взгляд, проще и эффективнее обратиться ко второму методу: сравнить объявляемые показатели с ожидаемыми инвесторами. В данном случае первоочередной задачей становится нахождение тех прокси, которые наилучшим образом в данной ситуации отражают ожидания инвесторов. Зачастую это прогнозные показатели аналитиков. За дополнительными пояснениями и идеями мы отсылаем читателя к первой части статьи (раздел «Фактор 1: хорошие и плохие новости»), где подробно разбирался вопрос ожиданий, a также к книге Коупленда и Долгоффа [Copeland and Dolgoff, 2005], посвященной управлению стоимостью компании через ожидания инвесторов.

На втором шаге мы пытаемся оценить, как рынок отреагирует на новость, которую компания собирается ему сообщить. Для этого мы должны определить значимые факторы для данной конкретной компании, которые комплексно и определят реакцию рынка. Это могут быть специфические параметры компании, такие как структура инвесторов (этот фактор, например, активно использует консалтинговая компания Boston Consulting Group, для выявления стратегии, которая больше всего понравится доминирующей части инвесторов и в результате увеличит акционерную стоимость капитала компании), история финансовых результатов (которая настраивает инвесторов на соответствующий тренд), положение в отрасли, размер компании, высокотехнологичность бизнес-процессов, имя и репутация управляющего (решениям которого безраздельно доверяют и оценивают положительно, даже если последствия таких решений неоднозначны, или наоборот) и многие другие факторы, которые мы обсуждали выше. Или же это могут быть факторы, которые оказывают мощное влияние на все компании на рынке в текущем периоде например, финансовый кризис, который перекрывает своим нисходящим давлением весь позитив хороших новостей. На этом этапе сосредоточен весь основной анализ, который позволит на следующем этапе скорректировать оптимальным образом объявление новости. Основные выводы и данные, которые могут помочь аналитику в этой непростой задаче, приведены во второй части статьи, где были довольно подробно разобраны различные факторы и их влияние на восприятие рынком корпоративных новостей. К сожалению, дать более жесткую схему анализа, формализовать его, не представляется возможным.

На третьем шаге мы уже располагаем оценкой реакции рынка на новость, полученной аналитически. Если предполагаемая реакция негативная, то компания может попробовать повлиять на реакцию рынка. Для этого она может: 
1) использовать семантические приемы (сместить акценты с основного негатива на нейтральную часть новости, смягчить негатив информации, используя эмоционально нейтральные слова для передачи той же информации, и т.д.);

2) «разбавить» эту плохую новость хорошей (в частности, закончить сообщение негативной информации фразой о незначительном эффекте данного события, а также оптимистичными перспективами);

3) задействовать каналы распространения новости в оптимальном порядке.

Последний пункт требует более подробного раскрытия. Идея заключается в том, что в зависимости от «знака» новости (хорошая она или плохая) и преобладающего типа инвесторов в структуре собственности (индивидуальные или институциональные инвесторы) компании выгоднее использовать сначала канал аналитиков, а потом публичное объявление или наоборот. Дело в том, что эмпирически установлено (в частности, в работе Вомака [Womack, 1996]), что рынок (а именно индивидуальные инвесторы) реагирует на рекомендации и другую оценочную информацию, исходящую от аналитиков, даже в том случае, если эта информация уже известна рынку и учтена в ценах акций. Таким образом, если у компании плохие новости и сначала она объявляет их рынку, а потом вдобавок появляются негативные рекомендации или прогнозы аналитиков, написанные на основе той же информации, то компания рискует, что рынок среагирует дважды на одну и ту же новость, притом дважды негативно. Когда же на рынок сначала поступает негативный прогноз от аналитиков, а потом уже информация, вызвавшая этот прогноз, рынок реагирует только на прогноз аналитиков. Поэтому для компании, среди внешних акционеров которой много индивидуальных инвесторов, лучше сообщать о плохих новостях сначала аналитикам, а потом, после публикации мнения аналитиков, объявлять их непосредственно рынку. Можно также попробовать воспользоваться этим эффектом, чтобы усилить положительную реакцию рынка на хорошие новости. То есть сначала объявить хорошие новости рынку, чтобы он среагировал на них, а потом с некоторым запозданием сообщить те же новости аналитикам. Они опубликуют хорошие рекомендации и прогнозы, и рынок среагирует на них повторно, в результате чего компания добьется более высокого роста котировок. Иная ситуация, если в структуре держателей акций преобладают институциональные инвесторы. Этот тип инвесторов существенно отличается от индивидуальных - у них больше опыта, есть экономическое или финансовое образование, и, кроме того, у них есть свои аналитические отделы. Если к тому же доля такого инвестора достаточно велика, то, скорее всего, инвестор принимает непосредственное участие в управлении компанией или, по крайней мере, хорошо осведомлен о том, что в ней в реальности происходит. Поэтому институциональные инвесторы гораздо более адекватно реагируют на новости компаний, а также на прогнозы и рекомендации других аналитиков. Соответственно, нет никакой необходимости задействовать внешних аналитиков для разъяснения инвесторам значения того или иного события для компании. Поэтому можно одновременно сообщать всю информацию и аналитикам, и инвесторам.

Итак, предложенная методика анализа лаконична и проста, но, как уже стало ясно из статьи, это только суть того, что необходимо сделать, так сказать, надводная часть айсберга - очевидно, что за этим скрывается самая большая и нетривиальная работа, которую по объему уместно сопоставить с подводной частью айсберга.

\section{Заключение}

В данной статье была предпринята попытка выяснить, как рыночная стоимость меняется в ответ на объявление тех или иных корпоративных новостей, и описать данный процесс в концептуальной модели. Мы систематизировали все доступные данные эмпирических исследований, изучающих различные аспекты влияния новостей на рыночную стоимость компании. Такая систематизация, а также критический анализ исследований - их гипотез, выборок, методов — позволили нам получить обобщенную, целостную картину 
процесса влияния новости на рыночную стоимость компании. Мы пришли к выводу, что реакция рынка на объявляемую новость зависит от четырех групп факторов: (1) параметры новости, т.е. что именно поступает на рынок; (2) каналы распространения новости, т.е. как новость поступает на рынок; (3) контекст восприятия инвесторами новости, т.е. где, в каком контекстовом окружении оказывается новость; (4) тип инвесторов, т.е. кто получает и использует новость в инвестиционных решениях. Факторы каждой группы определенным образом влияют на восприятие инвесторами новости и соответственно на итоговую реакцию рынка. В связи с этим компания должна иметь в виду, что рынок обращает внимание не только на «знак» новости - хорошая она или плохая, на восприятие инвесторами новости влияют и новости конкурентов, и параметры компании, и общее состояние фондового рынка, и непосредственно предпочтения и ожидания заинтересованной группы инвесторов, и многое другое. Более того, в каждом конкретном случае, для каждой конкретной компании значимые факторы могут быть разными, и влияние их на итоговое изменение рыночной стоимости компании тоже может быть разным. Ввиду этого мы убеждены, что наиболее эффективным и плодотворным подходом в моделировании влияния новости на рыночную стоимость компании будет не математический и не эконометрический, а концептуальный. Предложенная нами модель описывает принципы влияния новости на рыночную стоимость. В основе реакции рынка на новость лежат базовые психологические механизмы, а именно особенности восприятия, внимания, памяти и эмоций инвесторов. Именно эти особенности и обуславливают логику реакции рынка на поступающую информацию. Для того чтобы модель можно было использовать в практических целях, в управлении рыночной стоимостью компании, мы разработали методику анализа влияния новости на стоимость компании. Она предлагает определенную логику анализа, три последовательные шага: (1) определить, как инвесторы воспримут новость - как хорошую или как плохую; (2) оценить реакцию рынка на новость с учетом уже определенного «знака» новости; (3) скорректировать по возможности предполагаемую реакцию рынка. Самое важное в этой методике - это анализ на каждом шаге, его содержание и то, какими средствами будут решаться поставленные задачи. В решении задач нам помогут исследовательские подходы (методы и метрики) и результаты эмпирических исследований, которые мы систематизировали и анализировали в первой части работы.

\section{Список литературы}

1. Copeland, T., and Dolgoff, A. Outperform with expectations-based management. - New Jersey: John Wiley \& Sons, Inc., 2005.

2. Abarbanell, J., and Lehavy, R. Biased forecasts or biased earnings? The role of earnings management in explaining apparent optimism and inefficiency in analysts' earnings forecasts // Unpublished paper, University of North Carolina, 2000.

3. Agrawal, A., Jaffe, J.F., and Mandelker, G. (1992), The post-merger performance of acquiring firms in acquisitions: a re-examination of an anomaly, Journal of Finance, 47 (1992) 1605-1621.

4. Amir, E., Lev, B., and Sougiannis, T. What value analysts? // Working paper, 1999.

5. Baker, M., and Wurgler, J. (2004a), A catering theory of dividends, Journal of Finance, 59 (2004a) 271-288.

6. Baker, M., and Wurgler, J. (2004b), Appearing and disappearing dividends: The link to catering incentives, Journal of Financial Economics (2004b), forthcoming.

7. Barberis, N., Shleifer, A., and Vishny, R. (1998), A model of investor sentiment, Journal of Financial Economics, 49 (1998) 307-343.

8. Basu, S.,(1983), The relationship between earnings yield, market value, and return for NYSE common stocks: Further evidence, Journal of Financial Economics, 12 (1983) 129_ 156.

9. Bernard, V., and Thomas, J. (1989), Post-earnings announcement drift: Delayed price 
response or risk premium?, Journal of Accounting Research (Suppl.), 27 (1989) 1-36.

10. Bernard, V., Thomas, J., and Wahlen, J. (1997), Accounting based stock price anomalies: Separating market inefficiencies from risk, Contemporary Accounting Rensearch, 14 (1997) $89-136$.

11. Brown, L. (2001), A temporal analysis of earnings surprises: Profits versus losses, Journal of Accounting Research, 39 (2001), 221-241.

12. Campbell, J., Grossman, S., and Wang, J. (1993), Trading volume and serial correlation in stock returns, Quarterly Journal of Economics, 108 (1993), 905-940.

13. Chan, L., Jegadeesh, N., and Lakonishok, J. (1997), Momentum strategies, Journal of Finance, 51 (1997), 1681-1713.

14. Chan, L., and Lakonishok, J. (1995), The behavior of stock prices around institutional trades, Journal of Finance 50 (1995), 1147-1174.

15. Chan, W. (2003), Stock price reaction to news and no-news: drift and reversal after headlines, Journal of Financial Economics 70 (2003), 223-260.

16. Chopra, N., Lakonishok, J., and Ritter, J. (1992), Measuring abnormal performance: do stocks overreact? // Journal of Financial Economics 31 (1992), 235-268.

17. Cohen, R., Gompers, P., and Vuolteenaho, T. (2002), Who underreacts to cash-flow news? Evidence from trading between individuals and institutions, Journal of Financial Economics, Vol. 66, Iss. 2, 3 (2002), p. 409.

18. Conrad, J., Cornell, B., and Landsman, W. (2002), When is bad news really bad news? The Journal of Finance, Vol. LVII, No.6, (2002), 2507-2532.

19. Cutler, D., Poterba, J., and Summers, L. (1991), Speculative dynamics, Review of Economic Studies 58 (1991), 529-546.

20. Daniel, K., Hirshleifer, D., and Subrahmanyam, A. (1998), A theory of overconfidence, self-attribution, and security market under- and over-reactions, Journal of Finance 53 (1998), in press.

21. David, A. (1997), Fluctuating confidence in stock markets: Implications for returns and volatility, Journal of Financial and Quantitative Analysis 32, (1997), 427-482.

22. De Bondt, W., and Thaler, R. (1985). Does the stock market overreact? Journal of Finance 40 (1985), 793-808.

23. Dechow, P., and Sloan R. (1997), Returns to contrarian investment strategies: Tests of naive expectations hypotheses, Journal of Financial Economics, 43 (1997), 3-27.

24. Edwards, W. (1968), Conservatism in human information processing, in: Kleinmutz, B. (Ed.). Formal Representation of Human Judgment. John Wiley and Sons, New York, p. $17-52$.

25. Ekholm, A. (2002), How do different types of investors react to new financial statement information? Swedish School of Economics and Business Administration Working Paper No. 464.

26. Fama, E. (1998), Market efficiency, long-term returns, and behavioral finance, Journal of Financial Economics, 49 (1998), 283-306.

27. Fama, E., and French, K. (1992), The cross-section of expected stock returns, Journal of Finance, 47 (1992), 427-465.

28. Fama, E., and French, K. (1993), Common risk factors in the returns on stocks and bonds, Journal of Financial Economics, 33 (1993), 3-56.

29. Fama, E., and French, K. (1995), Size and book-to-market factors in earnings and stock returns, Journal of Finance 50 (1995), 131-155.

30. Fama, E., and French, K. (1996), Multifactor explanation of asset pricing anomalies, Journal of Finance, 51 (1996), 55-84.

31. Foster, F.D., and Viswanathan, S. (1996), Strategic trading when agents forecast of others, Journal of Finance, 51 (1996), 1437-1478.

32. Gompers, P., and Lerner, J. (1998), Venture capital distributions: short-run and long-run reactions, Journal of Finance 53 (1998), 2161-2183. 
33. Hong, H., and Stein, J. (1999), A unified theory of underreaction, momentum trading and overreaction in asset markets, Journal of Finance, 54 (1999), 2143-2184.

34. Hong, H., Lim, T., and Stein, J. (2000), Bad news travels slowly: size, analyst coverage, and the profitability of momentum strategies, Journal of Finance 55 (2000), 265-295.

35. Ikenberry, D., and Lakonishok, J. (1993), Corporate governance through the proxy contest: Evidence and implications, Journal of Business 66 (1993), 405-435.

36. Ikenberry, D., Lakonishok, J., and Vermaelen, T. (1995), Market underreaction to open market share repurchases, Journal of Financial Economics 39 (1995), 181-208.

37. Ikenberry, D., and Ramnath, S. (2002), Underreaction to self-selected news events: the case of stock splits, Review of Financial Studies 15 (2002), 489-526.

38. Ikenberry, D., Rankine, G., and Stice, E. (1996), What do stock splits really signal? Journal of Financial and Quantitative Analysis, 31 (1996), 357-375.

39. Jegadeesh, N. (1990), Evidence of predictable behavior of security returns, Journal of Finance 45 (1990), 881-898.

40. Jegadeesh, N., and Titman, S. (1993), Returns to buying winners and selling losers: implications for stock market efficiency, Journal of Finance 48 (1993), 65-91.

41. Kahneman D., and Tversky, A. (1979), Prospect Theory: An Analysis of Decision Under Risk, Econometrica, 47 (1979), 263-91.

42. Kothari, S., Sabino, S., and Zach, T. (1999), Implications of data restrictions on performance measurement and tests of rational pricing, Unpublished paper, Massachussets Institute of Technology, Cambridge, MA, 1999.

43. Kothari, S., Shu, S., and Wysocki, P. (2008), Do Managers Withhold Bad News? MIT Sloan Research Paper No. 4556-05, 2008.

44. Kyle, A. (1985), Continious auctions and insider trading, Econometrica 53 (1985), 13151335.

45. La Porta, R. (1996), Expectations and the cross-section of expected returns, Journal of Finance 51 (1996, 1715-1742.

46. La Porta, R., Lakonishok, J., Shleifer, A. and Vishny, R. (1997), Good news for value stocks: Further evidence on market efficiency, Journal of Finance 52 (1997), 859-874.

47. Lakonishok, J., Shleifer, A., and Vishny, R. (1994), Contrarian investment, extrapolation, and risk, Journal of Finance 49 (1994), 1541-1578.

48. Lee, C. (1992), Earnings news and small traders, Journal of Accounting Economics, 15 (1992), 265-302.

49. Lo, A., and MacKinlay, A. (1990), When are contrarian profits due to stock market overreaction? Review of Financial Studies 3 (1990), 175-205.

50. Loughran, T., and Ritter, J. The new issues puzzle, The Journal of Finance 50 (1995), 2352.

51. Michaely, R., Thaler, R., and Womack, K. (1995), Price reactions to dividend initiations and omissions: overreaction or drift? Journal of Finance 50 (1995), 573-608.

52. Michaely, R., and Womack, K. (1999), Conflict of interest and the credibility of underwriter analyst recommendations, Review of Financial Studies 12 (1999), 653-686.

53. Mitchell, M., and Mulherin, J. (1994), The impact of public information on the stock market, Journal of Finance 49 (1994), 923-950.

54. Pritamani, M., and Singal, V. (2001), Return predictability following large price changes and information releases, Journal of Banking and Finance 25 (2001), 631-656.

55. Ritter, J. (1991), The long-run performance of initial public offerings, Journal of Finance, 46 (1991), 3-27.

56. Roll, R. (1988), R ${ }^{2}$, Journal of Finance, 43 (1988), 541-566.

57. Rouwenhorst, K. (1998), International momentum strategies, Journal of Finance, 53 (1998), 267-284.

58. Seyhun, H. (1997), Investment Intelligence: Tips from Insider Trading. - Cambridge: MIT Press, MA, 1997. 
59. Schwert, G. (1981), The adjustment of stock prices to information about inflation, Journal of Finance, 36 (1981), 15-29.

60. Skinner, D. (1997), Earnings disclosures and stockholder lawsuits, Journal of Accounting \& Economics 23 (1997), 249-282.

61. Skinner, D., and Sloan, R. (2002), Earnings surprises, growth expectations and stock returns or Don't let an earnings torpedo sink your portfolio, Review of Accounting Studies 7 (2002), 289-312.

62. Soffer, L., Thiagarajan, S., and Walther, B. (2000), Earnings preannouncement strategies, Review of Accounting Studies 5 (2000), 5-26.

63. Spiess, K., and Affleck-Graves, J. (1995), Underperformance in long-run stock returns following seasoned equity offerings, Journal of Financial Economics 38 (1995), 243-267.

64. Statman, D. (1980), Book values and stock returns, The Chicago MBA: A Journal of Selected Papers 4 (1980), 25-45.

65. Veronesi, P. (1999), Stock market overreaction to bad news in good times: A rational expectations equilibrium model, Review of Financial Studies 12 (1999), 975-1007.

66. Womack, K. (1996), Do brokerage analysts' recommendations have investment value? Journal of Finance 51 (1996), 137-168. 